\title{
Role of exosomes in the immune microenvironment of ovarian cancer (Review)
}

\author{
XIAO LI $^{1}$, YANG LIU ${ }^{1}$, SHUANGSHUANG ZHENG ${ }^{1}$, TIANYU ZHANG ${ }^{1}$, \\ JING WU ${ }^{1}$, YUE SUN ${ }^{1}$, JINGZI ZHANG ${ }^{1}$ and GUOYAN LIU ${ }^{2}$ \\ Departments of ${ }^{1}$ Obstetrics and Gynecology and ${ }^{2}$ Gynecology, Tianjin Medical University General Hospital, \\ Tianjin 300052, P.R. China
}

Received September 27, 2020; Accepted January 27, 2021

DOI: $10.3892 / 01.2021 .12638$

\begin{abstract}
Exosomes are excretory vesicles that can deliver a variety of bioactive cargo molecules to the extracellular environment. Accumulating evidence demonstrates exosome participation in intercellular communication, immune response, inflammatory response and they even play an essential role in affecting the tumor immune microenvironment. The role of exosomes in the immune microenvironment of ovarian cancer is mainly divided into suppression and stimulation. On one hand exosomes can stimulate the innate and adaptive immune systems by activating dendritic cells (DCs), natural killer cells and T cells, allowing these immune cells exert an antitumorigenic effect. On the other hand, ovarian cancer-derived exosomes initiate cross-talk with immunosuppressive effector cells, which subsequently cause immune evasion; one of the hallmarks of cancer. Exosomes induce the polarization of macrophages in M2 phenotype and induce apoptosis of lymphocytes and DCs. Exosomes further activate additional immunosuppressive effector cells (myeloid-derived suppressor cells and regulatory $\mathrm{T}$ cells) that induce fibroblasts to differentiate into cancer-associated fibroblasts. Exosomes also induce the
\end{abstract}

Correspondence to: Dr Guoyan Liu, Department of Gynecology, Tianjin Medical University General Hospital, 154 Anshan Road, Heping, Tianjin 300052, P.R. China

E-mail: liuguoyan211@126.com

Abbreviations: APCs, antigen presenting cells; CAFs, cancer-associated fibroblasts; CTL, cytotoxic lymphocyte; DCs, dendritic cells; EGF, epidermal growth factor; EMC, extracellular matrix component; EMT, epithelial-mesenchymal transition; HPMCs, human peritoneal mesothelial cells; HSP, heat shock protein; IL, interleukin; ILVs, intraluminal vesicles; lncRNA, long non-coding RNA; 5-LOX, 5-lipoxygenase; MDSCs, myeloid-derived suppressor cells; MHC, major histocompatibility complex; MMP, matrix metalloproteinase; PGRN, progranulin; TAMs, tumor-associated macrophages; Th, helper T cell; Tregs, regulatory $\mathrm{T}$ cells

Key words: exosome, ovarian cancer, immune microenvironment tumorigenicity of mesenchymal stem cells to exert additional immune suppression. Furthermore, besides mediating the intercellular communication, exosomes carry microRNAs (miRNAs), proteins and lipids to the tumor microenvironment, which collectively promotes ovarian cancer cells to proliferate, invade and tumors to metastasize. Studying proteins, lipids and miRNAs carried by exosomes could potentially be used as an early diagnostic marker of ovarian cancer for designing treatment strategies.

\section{Contents}

1. Introduction

2. Biological characteristics of exosomes

3. Cell signaling and exosome-mediated tumor immune microenvironment modification in ovarian cancer

4. Immune cells

5. Immunosuppressive effector cells

6. Exosomal miRNAs, proteins and lipids in the tumor microenvironment

7. Significance of exosomes in ovarian cancer immunotherapy

8. Conclusions

\section{Introduction}

Ovarian cancer is one of the three primary gynecological tumors, with a 5-year survival rate of $44 \%$. Due to its lack of specific clinical symptoms and practical measures for early diagnosis, $>75 \%$ patients are diagnosed in advanced stages and quickly become prone to drug resistance during treatment (1). Ovarian cancer cells can simultaneously regulate immune activation and suppression by presenting cancer antigens to immune cells, secreting cytokines and a large number of soluble factors, as well as releasing exosomes to the tumor microenvironment affecting the proximal and distal tissues. These influencing factors together form a complex interactome called the tumor immune microenvironment (2). Innate and adaptive immune cells can stimulate an antitumor response by recognizing cancer antigens via the antigen presenting cells (APCs) (3). In addition, immune cells, such as lymphocytes, macrophages, dendritic cells (DCs), mast 
cells and natural killer (NK) cells, can regulate angiogenesis, certain tumorigenic metabolic pathways and metastasis within the tumor microenvironment $(4,5)$. Exosomes have also been shown to play an important role in affecting the tumor immune microenvironment and ensuing immune responses, such as antigen presentation, migration, metastasis and tumor invasion. Previous research indicates that exosomes carry a number of immunologically active molecules [including major histocompatibility complex (MHC I), heat shock protein (HSP) and CD81] that can stimulate an antitumor immune response (6). Conversely, some studies have shown that exosomes will weaken the antitumor immune response to effect cancer progression by potentiating immune evasion (7-9). Analyzing the immune microenvironment of ovarian cancer and understanding the role of exosomes in cancer progression could play a vital role in its early diagnosis and designing an effective immunotherapy regimen.

\section{Biological characteristics of exosomes}

Biological characteristics and functions. As endogenous cellular components, exosomes are vesicles (30-100 nm) derived from the endosomal compartments called multivesicular bodies (Fig. 1) that are secreted by various cells into the extracellular microenvironment. When exosomes are isolated by density gradient centrifugation or ultracentrifugation, they appear as round vesicles in solution. The ultrastructure is resolved by dehydration, where it appears cup-shaped under an electron microscope (10). Exosomes are double-membraned organelles formed by periodic endocytosis of intracellular fluid throughout the life cycle of eukaryotic cells. As early endosomes mature and develop into late endosomes, the inner membrane sprouts inward to form intraluminal vesicles (ILVs), which contain randomly engulfed parts of the cytoplasmic content, rich with mRNAs, microRNAs (miRNAs/miRs), proteins and lipids. ILVs that are released to the extracellular environment are called exosomes (11). Studies show that exosomes can be found in various extracellular fluids, such as blood, urine, ascites, semen and cerebrospinal fluid.

Exosomes can be used as delivery vehicles for a variety of bioactive molecules, for example proteins, lipids, mRNA, miRNA, long non-coding RNA (lncRNA), genomic DNA and cDNA. This unique composition is also occasionally used as an identifier for a particular exosome (12). Previous research indicates that the common proteins in exosomes include tetraspanins, co-stimulatory molecule CD86 and adhesion molecules, such as integrins, ICAM1, CD166 and CD146. Besides specialized proteins, exosomes may also carry common proteins, such as HSP-70, HSP84 and HSP90 (11). Exosomes can accelerate peptide loading onto MHC I and II, thereby mediating a rapid immune response. Exosomes also carry signal transduction proteins, for example, receptor tyrosine kinases and membrane transport and fusion proteins, such as the GTPases Rab5 and Rab7 (11). Studies have also reported that nucleic acids are carried by exosomes, comprising of a diverse mix of DNA $(13,14)$, RNA (15), lncRNA (16) and miRNA $(17,18)$ molecules. Exosomal miRs (miR-15, -16, 151 and -375) can promote angiogenesis and tumor progression in the TME (11). The bioactive cargo carried by exosomes can participate in the modification of immune response of an ovarian cancer microenvironment (19).

Exosome involvement in pathological conditions. In infectious and non-infectious pathological conditions, both non-tumorous and tumorous cells tend to release exosomes more actively, whereas the number of exosomes quantified from the blood of patients with ovarian cancer is 3-4 times higher compared with in healthy individuals (11). The exosomes extracted from two human ovarian carcinoma cell lines OVCAR-3 and IGROV1 have a density ranging from 1.09-1.15 g/ml, while $\sim 2,230$ proteins are detected in the exosomal cargo, including other significant exosomal protein markers (20). Andre et al (6) in 2002 detected human epidermal growth factor (EGF) receptor (Her2/neu gene) signaling in exosomes of patients with ovarian cancer via western blotting. Activated matrix metalloproteinase (MMP)-2, MMP-9 and urokinase plasminogen activator are found in exosomes derived from the ascites of patients with ovarian cancer, which promotes protease activation to increase degradation of the extracellular matrices (ECMs) and tumor cell invasion and metastasis (21).

\section{Cell signaling and exosome-mediated tumor immune microenvironment modification in ovarian cancer}

The tumor microenvironment is the product of a number of cells and their accompanying extracellular matrix component (EMCs) jointly contributing towards the development of a distinct microenvironment surrounding the tumor mass. The cells comprise of stromal cells, including: Fibroblasts, macrophages, myeloid-derived suppressor cells, endothelial cells and mesenchymal stem cells. EMCs comprise of inflammatory cytokines, chemokines, MMPs, integrins and exosomes (22) (Fig.2). Tumor cells interact with stromal cells to promote angiogenesis, infiltration and metastasis that cause the tumor to grow and invade other tissues (23). TNF- $\alpha$ is a pro-inflammatory cytokine that is secreted primarily by macrophages along with other cells of the stroma, which promotes tumor necrosis or apoptosis. In total, $\sim 28 \%$ of all cancer types are affected by TNF-mediated necrosis (24). 5-Lipoxygenase (5-LOX) is a member of the lipoxygenase family of genes that is a key enzyme in the conversion of arachidonic acid to leukotrienes. In ovarian cancer, upregulation of 5-LOX metabolites and TNF- $\alpha$ can promote recruitment of macrophages to the tumor site (25). In addition, the pro-inflammatory interleukin-6 (IL-6) has been shown to be an important cytokine in the ovarian cancer tumor microenvironment. IL-6 can mediate the maturation of macrophages into M2 macrophages, which enhance tumor vascular stability by VEGF and TGF- $\beta 1$, thus promoting tumor progression (26-29). Upregulation of miR-217 in ovarian cancer downregulates the IL-6-dependent JAK3/STAT3 signaling pathway, thereby potentially inhibiting the maturation of macrophages from M1 to M2 stage (30). Ovarian cancer-associated mesenchymal stem cells (MSCs) highly express IL-6 and leukemia inhibitor factor that activate the JAK3/STAT3 signaling pathway to increase the tumorigenicity of ovarian cancer stem cells (31). Wang et al (32) have found that cancer-associated fibroblasts (CAFs) can also secrete IL-6 and promote the accumulation 


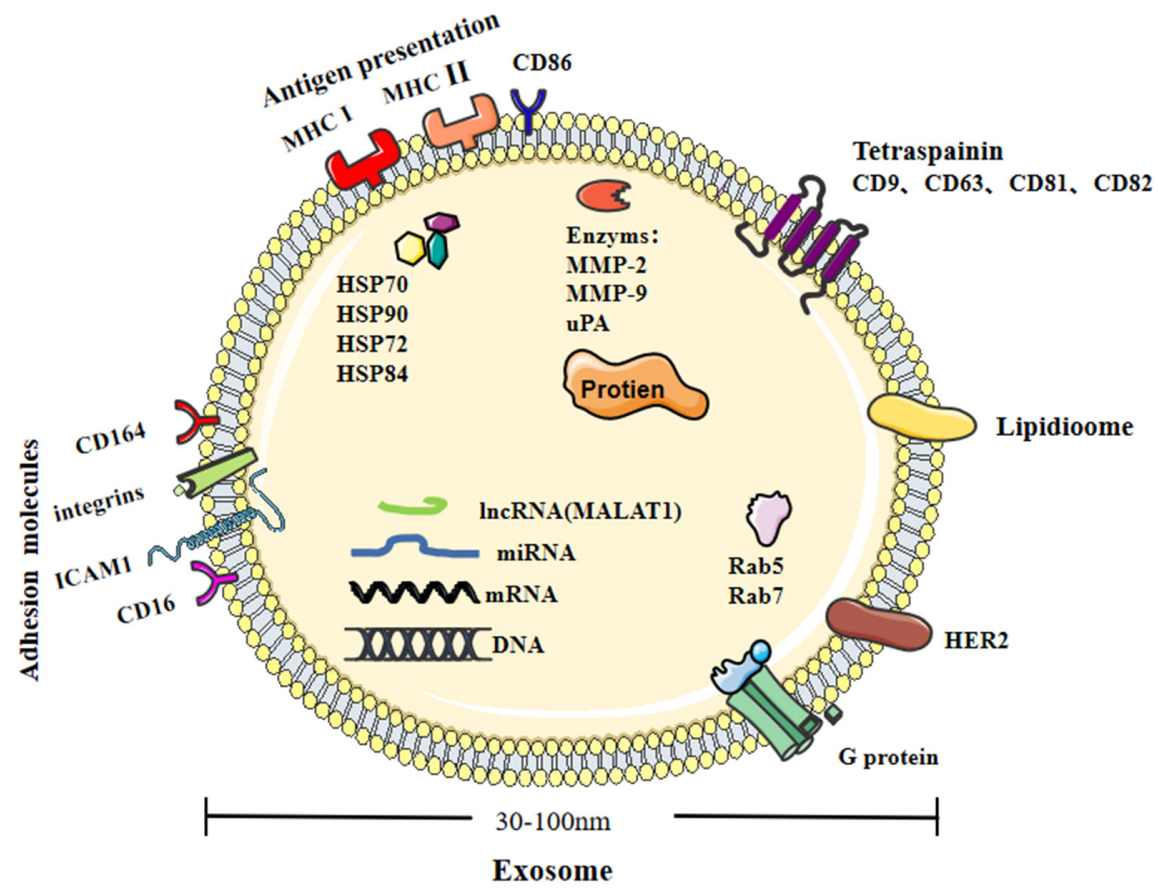

Figure 1. Biological characteristics of exosomes. Diameter of exosomes is between 30-100 nm. Exosomes carry proteins, lipids, enzymes, mRNAs, microRNAs and lncRNAs. Tetraspanin and adhesion molecules can be found on the surface of exosomes, including: Costimulatory molecules (CD86), integrins, ICAM1, CD166 and CD146. Exosomes carry proteins including heat-shock proteins HSP70, HSP84 and HSP90, which make the binding between MHC I and MHC II with peptide more rapid. Signal transduction proteins (G-proteins and protein kinases) and membrane transport and fusion proteins (Rab5 and Rab7) can be found on the surface, in addition to the Her2 signal. lncRNA, long non-coding RNA; MHC, major histocompatibility complex.

of ovarian cancer stem cells in residual tumors by activating the STAT3 signaling pathway. Exosomes derived from ascites in patients with ovarian cancer can promote the release of more IL- 6 from monocytes (THP-1 cells) and activate the NF-kB and STAT3 signaling pathways, which leads to a cytokine environment conducive for immune evasion of tumor cells (33). In addition, IL-6 has been associated with chemotherapy resistance and poor prognosis in patients with ovarian cancer. Studies have shown that the level of IL-6 in the serum of patients with cancer is significantly higher compared with that of normal individuals $(34,35)$. IL- 6 can upregulate the expression of resistance-related genes multi-drug resistance-1 and glutathione S-transferase $\pi$; in addition to the expression of apoptosis inhibitor protein. Moreover, IL-6 can activate the Ras/MEK/ERK and PI3K/Akt signaling pathways that jointly induce chemotherapy resistance $(34,36)$. The value of IL-6 as a prognostic and diagnostic indicator of ovarian cancer has been confirmed $(37,38)$.

Studies suggest that a higher ratio of M2:M1 macrophages is associated with poor prognosis in patients with ovarian cancer, whereas a higher ratio of M1:M2 macrophages is associated with good prognosis $(39,40)$. Some investigations have shown that tumor-associated macrophages (TAMs) can activate the MMP9/HB-EGF pathway along with the production of EGF to promote ovarian cancer and breast cancer progression $(41,42)$. TGF- $\beta$ can promote the transformation of epithelial cells to mesenchymal cells, promoting angiogenesis and inducing immunosuppression, subsequently promoting tumor progression (43). TAMs release TGF- $\beta 1$ and tenascin-C to promote tumor metastasis in ovarian cancer (44). CAFs can also promote invasion and metastasis of ovarian cancer in the tumor microenvironment $(45,46)$. Studies have shown that TGF- $\beta 1$ secreted by CAFs can notably potentiate the mechanism of epithelial-mesenchymal transition (EMT), thereby promoting bladder cancer to metastasize (47). Similarly, CAFs highly express the $T G F-\beta$ gene in ovarian cancer (48). In addition, studies have shown that CAFs in ascites can promote the production of multicellular aggregates, thereby promoting peritoneal metastasis $(46,49)$. CAFs highly express $\mathrm{X}$-linked sushi repeat-containing protein, which are peroxiredoxin enzymes that control cytokine-induced peroxide levels. Similarly, CAFs also highly express hemicentin- 1 genes in ovarian cancer tissue samples. Sequential knock-down of these two genes can weaken the ability of CAFs to promote ovarian cancer metastasis (50). Myeloid-derived suppressor cells (MDSCs) and Tregs are important components of the tumor immune evasion mechanism $(51,52)$. A previous study confirmed that the co-culture of MDSCs and ovarian cancer cells can promote the formation of tumor spheres, cell colonies and the accumulation of cancer stem cells, thus a strong indication that MDSCs can induce tumor progression (53). VEGF-induced MDSCs inhibit the activity of $\mathrm{CD}^{+} \mathrm{T}$ cells in ovarian cancer, weakening the host's antitumor immune response and leading to a poor prognosis (54). A study showed that a higher count of Treg cells could be detected in the peripheral blood of patients with ovarian cancer and thus is associated with poor prognosis (55).

In addition to stromal cells, non-cellular components are also included in the tumor microenvironment. TGF- $\beta$ is a major cytokine in the tumor microenvironment. TGF- $\beta$ combines with SMADs, the main signal transducers for TGF- $\beta$ receptors, to activate cells, which can promote 


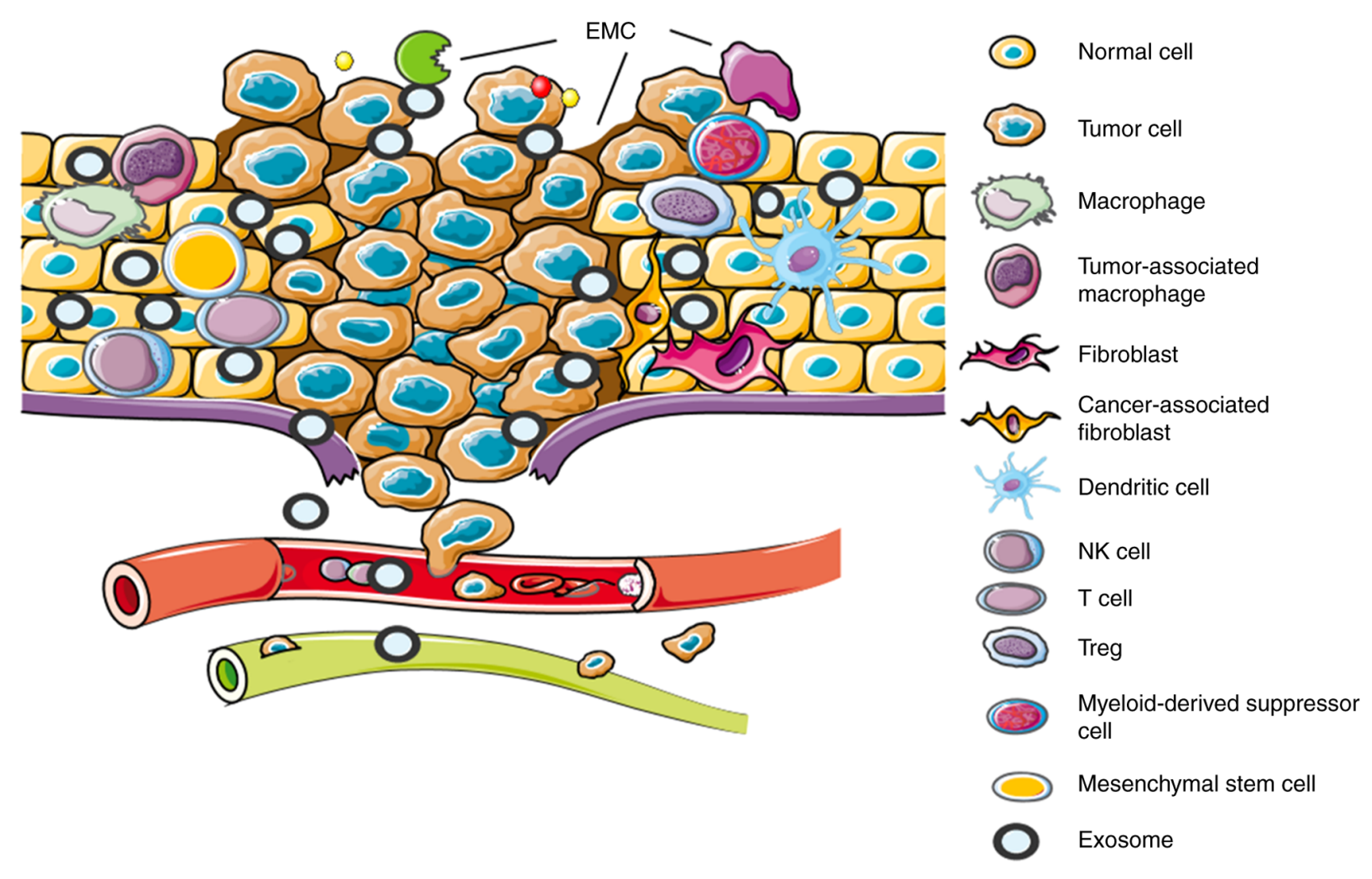

Figure 2. Ovarian cancer immune microenvironment. Tumor microenvironment consists of stromal cells (including fibroblasts, macrophages, Tregs, myeloid-derived suppressor cells, endothelial cells, mesenchymal stem cells), extracellular matrix components and exosomes. EMC, extracellular matrix component; NK, natural killer cells; Treg, regulatory T cells.

transformation of fibroblasts and regulate cell proliferation and apoptosis (56). The high expression of TGF- $\beta 3$ is associated with poor prognosis of high-grade serous carcinoma, and it is a potential indicator for the evaluation of ovarian cancer prognosis (57). Recent studies have reported that in ovarian cancer stem cells, inhibition of TGF- $\beta /$ SMAD pathway activation can further inhibit EMT (58-60). In 2012, Kulbe et al (61) first described the 'TNF' network in the ovarian cancer microenvironment. 'TNF' network means that TNF, CXCL12 and IL-6 have a paracrine effect in the tumor microenvironment, affecting angiogenesis and immune cell infiltration. In addition, cytokine-induced tumor cells can release guanylate binding-protein-1 and have an antitumor effect (62). The role of cytokines in the tumor microenvironment provides new possibilities for the treatment of ovarian cancer.

As an essential constituent of the tumor microenvironment, the role of exosomes in the tumor microenvironment can be summarized into two aspects, namely tumor-promoting and tumor-inhibiting. Exosomes modulate immune regulation to reshape the tumor microenvironment through metabolism-regulation, stimulation signal upregulation and inhibition signal evasion $(63,64)$. Exosomes induce angiogenesis by changing the biological characteristics of endothelial cells and regulating pro-angiogenic factors (65). In addition, exosomes may induce human hepatocellular carcinoma metastasis and invasion through EMT, ECM degradation and vascular leakage (66). Ras-like in rat brain (Rab) protein is a member of the GTPase family and plays an important role in regulating the budding, movement and fusion of microvesicles. Studies have shown that ovarian cancer cells can increase the release of exosomes by upregulating Rab27a, downregulating Rab7, lysosome-associated membrane protein-1, neuraminidase-1 mRNA and therefore promoting the secreted lysosomal phenotype $(67,68)$. In addition, the hypoxia-induced exosomes carry oncogenic proteins STAT3 and FAS, which can significantly increase ovarian cancer cell migration, invasion and chemotherapy resistance (67). Epithelial ovarian cancer cells transfer metastasis-associated lung adenocarcinoma transcript-1 a lncRNA to human umbilical vein endothelial cells through exosomes, activating the expression of genes related to angiogenesis (69). Tang et al (70) demonstrated that ascites-derived exosomes highly express soluble E-cadherin, which can promote angiogenesis and ovarian cancer progression. The immune response regulated by exosomes also plays a role in suppressing tumor progression. Exosomes derived from ascites in patients with ovarian cancer can detect $\mathrm{T}$ cell receptors, CD20 and human leukocyte antigen-DR isotype (HLA-DR), in addition to histones H2A, B7-2 and HER2/neu gene, in order to participate in immune modulation (21). In addition, exosomes extracted from ascites of patients with ovarian cancer can induce apoptosis, inhibit proliferation, invasion and metastasis of tumor cells as they exert an antitumorigenic effect $(21,71)$.

As aforementioned, the tumor immune microenvironment is a product of immune cells and immune molecules that inhibit the proliferation of tumor cells (3). There are also a variety of components that can promote the proliferation and 


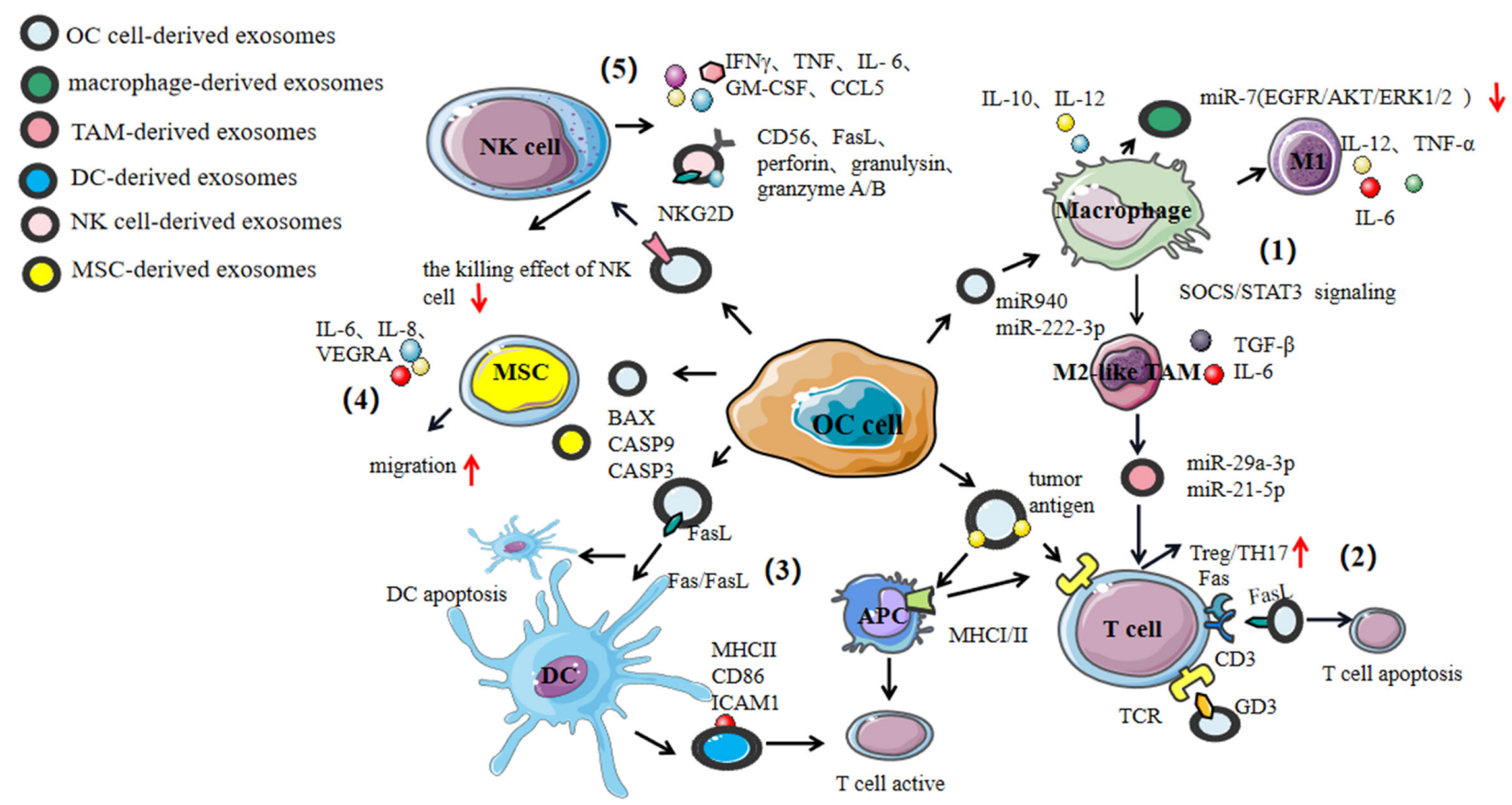

Figure 3. Exosomes cross-talk with immune cells in ovarian cancer immune microenvironment. Exosomes have a dual role in tumor immunity. (1) Exosomal miRNA induce M2-like macrophages (TAMs) to promote the progression of ovarian cancer, and macrophage-derived exosomes to exert the antitumor effect via miR-7. TAM-derived exosomes regulate the ratio of Treg/TH17. (2) Ovarian cancer cell-derived exosomes induce T cell apoptosis by Fas/FasL and FasL/CD3, and active T cell by presenting tumor antigens. (3) Ovarian cancer cell-derived exosomes induce DC apoptosis by Fas/FasL, DC-derived exosomes express MHCII, CD86 and ICAM1 to active T cell. (4) Ovarian cancer cell-derived exosomes enhance the migration of MSC, and exosomes derived from MSC upregulate pro-apoptotic signaling molecules (BAX, CASP9 and CASP3) to inhibit the progression of ovarian cancer. (5) Ovarian cancer cell-derived exosomes downregulate the killing effect of NK cell, NK cell-derived exosomes express NKG2D/DNAM-1 to kill the tumor cell and antitumor protein (CD56), FasL, perforin, granulysin, granzyme A and B. miR, microRNA; TAM, tumor-associated macrophages; DC, dendritic cells; MHC, major histocompatibility complex; NKG2D/DNAM-1, natural killer group 2, member D/DNAX accessory molecule-1; MSC, mesenchymal stem cells; CASP, caspase; OC, ovarian cancer.

invasion of tumor cells, including immunosuppressive cells such as Tregs, TAMs, CAFs, MDSCs and some immunosuppressive signaling factors (72).

\section{Immune cells}

In the tumor immune microenvironment, the host gives an innate immune response against the tumor mass while an adaptive immune response is given against the tumor antigens, thus preventing tumor progression. Innate immune cells include NK cells, macrophages and DCs. Adaptive immune effectors include $\mathrm{CD}^{+}$, cytotoxic $\mathrm{T}$ lymphocyte $(\mathrm{CTL})$ and $\mathrm{CD} 4^{+} \mathrm{Th}$ cells (72). Exosomes play a role in mediating cross-talk with immune cells to exert an antitumorigenic and/or a pro-tumorigenic effect (Fig. 3).

Macrophages. Macrophages are the first line of defense against foreign pathogens and key effectors of innate immunity, they are the key cells to bridge innate and adaptive immunities (73). According to their activation pathways, macrophages can be divided into two types: Classically-activated macrophages (named M1) and alternatively-activated macrophages (named M2) (74). Macrophages are usually polarized into M1 phenotype after being induced by IFN- $\gamma$, TNF- $\alpha$, IL- 6 and lipopolysaccharides. Their surface highly expresses MHC II and co-stimulatory proteins, such as CD80 and CD86 (75). M1 macrophages are generally considered pro-inflammatory and release IL-6, IL-12, TNF- $\alpha$ and reactive oxygen species
(ROS), which are considered intermediates that are associated with cytotoxicity and anti-tumorigenic properties (76,77). M2 macrophages are polarized by IL-4, IL-13, IL-10 and IL-33 (56). The markers on the surface of M2 macrophages include found in inflammatory zone 1 , mannose receptor 1 and MHC II (74). M2 macrophages have the capacity to secrete TGF- $\beta$, IL- 6 and arginase-1 to facilitate neovascularization, inhibit the adaptive immune response, ensure tumor cell survival and remodel the ECM, which are all generally considered as tumor-promoting functions $(78,79)$. In addition, TAMs are the main cells in the tumor immune microenvironment that have two phenotypes: M1-Like TAMs and M2-like TAMs (80). In the immune microenvironment of ovarian cancer TAMs usually manifest as the M2-like phenotype. The variety of biomarkers on the surface are scavenging receptor B (CD163), mannose receptor (CD204), IL-10 and chemotactic factor ligands CCL18 and CCL22 (81,82). IL-10 secreted by TAMs can activate Treg cells and promote tumor progression (83). miR-29a-3p and $-21-5 \mathrm{p}$, which are abundant in TAM-derived exosomes, can be transferred to $\mathrm{CD}^{+}{ }^{+} \mathrm{T}$ cells; thereby inhibiting STAT3 from regulating the ratio of Treg:Th17 and creating an immunosuppressive microenvironment that is necessary for the ovarian tumor to evade an active immune response, thus helping in tumor progression (84).

Tumor-derived exosomes can induce macrophages to differentiate into the M2 phenotype and TAMs, which have been confirmed in extracts from various organs, including: Ovaries, colorectal regions, endometrium, pancreas, melanoma, 
liver, breast and lung cancer cells (85-91). In a hypoxic microenvironment, high expression of miR-940 in exosomes has been derived from epithelial ovarian cancer cells, which induces macrophages to differentiate into the M2 phenotype, thus promoting proliferation and metastasis of epithelial ovarian cancer (92). Similar research shows that under hypoxic conditions, exosomes derived from epithelial ovarian cancer activate hypoxia-inducible factors that induce macrophages to highly express miR-21-3p,-125b-5p and -181d-5p and promotes their polarization to the M2 phenotype through the cytokine signal transduction 4/5/STAT3 signaling pathway, which was also verified in vivo. The JAK-STAT pathway mediates inflammatory immune response by converting cytokine signals, and SOCS is the key regulator of the pathway (76). Through microarray analyses, some researchers found that the expression of miR-221-3p was upregulated in exosomes that were derived from M2 macrophages. Additionally, miR-221-3p can target the inhibition of cyclin-dependent kinase inhibitor $1 \mathrm{~B}$, thus promoting the proliferation of ovarian cancer cells via transition from $G_{1}$ to $S$ (93). In addition, epithelial ovarian cancer-derived exosomes overexpress miR-222-3p and transfer it to macrophages to induce them into M2-like polarization by the SOCS3/STAT3 pathway. miR-222-3p targets downregulation of SOCS3 gene expression and activates STAT3 expression (94). This transfer of miR-222-3p can facilitate the progression of ovarian cancer (94). Wu et al (95) have shown that TAM-derived exosomes inhibit endothelial cell migration by targeting the miR-146b-5p/TRAF6/NF-kB/MMP2 pathway, whereas ovarian cancer-derived exosomes can reverse the role of TAMs in endothelial cells by transferring lncRNAs.

In order for macrophages to differentiate into TAMs, macrophage-derived exosomes are important components involved in the antitumor immune response $(84,93,96)$. The TNF-related weak inducer of apoptosis (TNSFS12 or TWEAK)-stimulated macrophage-derived exosomes can be internalized by the tumor cells, which can inhibit ovarian cancer metastasis. A study revealed that TWEAK-stimulation increased the expression of miR-7 (a tumor suppressor) in exosomes released by macrophages, which downregulates the activity of the EGFR/AKT/ERK1/2 signaling pathway and inhibits ovarian cancer metastasis (96). This was performed in mouse models where TWEAK-stimulated macrophage-derived exosomes blocked the metastasis of epithelial ovarian cancer (96). In addition, Baj-Krzyworzeka et al (97) have shown that tumor-derived exosomes can activate monocytes by increasing HLA-DR expression, upregulating reactive oxygen intermediates and TNF and by accumulating and secreting IL-10 and IL-12 mRNA. Exosomes activate monocytes and induce them to differentiate into macrophages (97-99). At present, there are few studies on macrophage-derived exosomes in ovarian cancer, which is an area that needs to be explored further. Exosomes derived from breast cancer cells have upregulated levels of miR-130 and miR-33, which can alter the polarization of macrophages from M2 to M1 phenotype and inhibit tumor progression (100). The exosomes derived from TAMs of progranulin (PGRN)-negative tumor tissues have upregulated expression of miR-5100, which inhibits the invasion, migration and EMT of breast cancer cells by targeting the CXCL12/CXCR4 axis (101). Although a similar study in ovarian cancer has not been performed, studies have shown that expression of PGRN protein relates to poor ovarian cancer prognosis $(102,103)$. Moreover, high expression of PGRN can induce EMT in ovarian cancer cells (104). This suggests that exosomes are a potential therapeutic target for ovarian cancer.

NK cells. In a tumor environment, NK cells are the first line of defense within the immune system. NK cells mainly kill target cells in four ways: i) Antibody-dependent cell-mediated cytotoxicity via the Fas/FasL pathway (105), ii) the perforin-granzyme pathway (106), iii) binding to target cells through adhesion molecules (107) and iv) releasing cytokines to attack target cells $(108,109)$. NK cells are important effectors in the cancer immune surveillance $(110,111)$. Upon activation, they secrete pro-inflammatory factors and chemokines, for example IFN- $\gamma$, TNF, IL-6, GM-CSF and chemotactic cytokine ligand 5 to mediate antitumor immune responses, affect antitumor activity and promote formation of the tumor microenvironment (112). IL-15 enhances the antitumor activity of NK cell-derived exosomes and has been validated in mouse models (113). Exosomes derived from NK cells express the killer protein (CD56), FasL, perforin, granulysin, and granzyme $\mathrm{A}$ and $\mathrm{B}$, which show antitumor activity and play a role in immune surveillance (114). Killer proteins expressed by NK cell-derived exosomes can participate in NK cell-mediated cytotoxic killing effects (115), and the expressed DNAX accessory molecule 1 (DNAM-1/CD226) receptor can bind to DNAM-1 ligands on the cell membrane of tumor cells to exert a cytotoxic tumor cell killing effect (116). This is an important role of NK cells in cancer immune surveillance. NK cell-derived exosomes express FasL and perforin and exert cytotoxic effects in melanoma (117). NK cell-derived exosomes carry miR-186, which can inhibit neuroblastoma growth (118). The antitumor effect of NK cell-derived exosomes on invasive melanoma and neuroblastoma has been confirmed, exosomes derived from NK cells can potentially be used in cancer treatment (117,118).

Although NK cells are a part of the innate immune system and are capable of killing tumor cells, tumor microenvironment also affects the cytotoxicity of NK cells (119). Exosomes released by ovarian cancer cells highly express KLRK1/ natural killer group 2 (NKG2D) ligands in the manner of MHC I chain-related protein A and B and UL16-binding protein. This downregulates the expression of NKG2D receptors on peripheral blood mononuclear cells, affecting the activation of NK cells and suppressing their natural killing effect (120).

Lymphocytes. Adaptive immune effector cells include $\mathrm{CD} 8^{+}$, $\mathrm{CTL}$ and $\mathrm{CD}^{+}{ }^{+} \mathrm{Th}$. In acute infection, CTL is the main effector cell and has a specific killing effect on tumors through the perforin-granzyme, Fas/FasL and TNF pathways (121). CD4 ${ }^{+}$Th cells play an auxiliary role in activating CTL (122). In contrast, during chronic infections and cancer, $\mathrm{T}$ cell dysfunction occurs due to continuous stimulation of antigens (123). In addition, the cytokines produced by $\mathrm{CD} 4^{+} \mathrm{Th}$ cells can indirectly participate in antitumor immune effects. In theory, dendritic cell-derived exosomes can stimulate $\mathrm{T}$ cells through three different mechanisms: i) Direct presentation of exosomal MHC I and II to T cells, ii) indirect stimulation 
via exosomal MHC presentation to APCs and iii) degradation and recycling of the exosomal $\mathrm{MHC}$ /peptide complex in the microenvironment (124).

Research shows that $\mathrm{T}$ cell-derived exosomes can regulate gene expression and extracellular signal transduction of DCs by carrying miRNA and T cell receptor protein (TCR)-rich vesicles (125). MHC I, MHC II and T cell co-stimulatory molecules on the surface of B lymphocyte-derived exosomes can stimulate the proliferation of $\mathrm{T}$ lymphocytes and thus prevent tumor progression (126). T follicular helper cell-derived exosomes facilitate the proliferation of B lymphocytes (127). $\mathrm{CD}^{+}{ }^{+} \mathrm{T}$ cell-derived exosomes regulate the gene expression of B lymphocytes by transporting their miRNA cargo to B lymphocytes, which therefore decreases the level of antibodies produced by B cells (128).

However, a previous study confirmed that tumor cell-derived exosomes recruit lymphocytes to suppress the antitumor immune response, promoting tumor progression by increasing tumor invasion, angiogenesis and upregulating proinflammatory cytokines, such as IL-6 and VEGFA (129). Exosomes can induce T cell apoptosis and weaken the immune response to achieve immune escape. FasL is a transmembrane protein in the TNF family of proteins that is increased in malignant tumors. FasL is overexpressed in tumor-derived exosomes (11,130). FasL recognizes the Fas receptor on the surface of target cells and triggers intrinsic apoptosis of target cells via the FADD-procaspase- 8 pathway, to induce T cell apoptosis and suppress the immune response (11). In addition, Fas can also mediate the apoptosis of lymphocytes through antibody-dependent direct cytotoxicity. A previous study has showed $41 \mathrm{kDa}$ FasL and HLA class I antigens are upregulated in ovarian cancer-derived exosomes and inhibit $\mathrm{T}$ cell antitumor immune function through FasL/CD3- $\zeta$ ligand-receptor binding (131). This inhibitory function has also been observed in other tumors, such as exosomes derived from human prostate cancer cells that induce $\mathrm{CD} 8^{+} \mathrm{T}$ cell apoptosis by FasL/Fas (132). FasL is also found in exosomes from melanoma and colorectal cancer, which is considered a new immune escape pathway (133). The expression of circ-0001068 (a novel biomarker for ovarian cancer and inducer of PD1 expression in T cells) in exosomes derived from ovarian cancer cells is upregulated and can be delivered to T cells as well. Once in $\mathrm{T}$ cells, circ-0001068 downregulates the expression level of miR-28-5p and thus induces the expression of PD1 (134). Exosomes released by ovarian cancer cells can carry plasma gelsolin and induce $\mathrm{CD} 8^{+} \mathrm{T}$ cell apoptosis, which weakens immune surveillance (135).

Exosomes from the ascites of patients with ovarian cancer can inhibit $\mathrm{T}$ cell signaling molecules, inhibit the expression of CD3- $\zeta$ and JAK 3, and induce T cell apoptosis (136). In the ascites of patients with ovarian cancer, the ganglioside GD3 expressed on the surface of exosomes binds with the TCR and actively arrest $\mathrm{T}$ cell function, which greatly reduces the antitumorigenic effect of T cells $(137,138)$. Moreover, a previous study showed that this inhibitory effect mediated by GD3 and TCR is related to the sialic acid group in exosomes (137). When the sialic acid group is hydrolyzed, this inhibitory effect disappears, which indicates that GD3 can be a new target for ovarian cancer immunotherapy (137). In addition, the ascites-derived exosomes of patients with ovarian cancer can effectively block
$\mathrm{T}$ cells in a reversible manner due to the early translocation of $\mathrm{NF}-\mathrm{kB}$ and later functional activation of IFN- $\gamma$. Researchers have demonstrated that this can be reversed within 24-48 h by the removal of exosomes. Therefore, targeted removal of exosomes will increase the antitumorigenic effect of the host T cells (139).

Tumor-derived exosomes can also inhibit T cell activation to cause immunosuppression. Functional CD39 and CD73 expressed by exosomes can dephosphorylate exogenous ATP and $\mathrm{cAMP}$ to form adenosine, and inhibit $\mathrm{T}$ cell activation through the adenosine A2A receptor. Therefore, exosomes increase the production of extracellular adenosine to regulate the antitumor immune effect of the T cells (140). In addition, phosphatidylserine (PS)-positive exosomes derived from the ascites of patients with ovarian cancer block the NF-kB and NFAT pathway signaling cascade in T cells, and reversibly inhibit T cell activation (141). Thus, depletion of anti-PS antibodies or blocking PS can notably eliminate the inhibition of $\mathrm{T}$ cells, which could be another new treatment method for patients with ovarian cancer (142).

DCs. DCs are unique, in that they can activate $\mathrm{T}$ cells. They can also activate immune responses or induce immune tolerance (143). Mast cell-derived exosomes contain HSP60 and HSP70, which can promote DC maturation and exert antitumorigenic immune effects in a mouse model (144). The ovarian cancer microenvironment is rich in cytokines and angiogenic factors, which can change the phenotype and function of DCs. Most studies corroborate that the ability of exosomes to stimulate $\mathrm{T}$ cells can be enhanced through the interaction of exosomes with DCs (145-147). Exosomes derived from the ascites of patients with ovarian cancer present tumor antigens and can induce differentiation of dendritic cells and tumor-specific cytotoxic T lymphocytes (6). Exosomes isolated from the ascites of patients with ovarian cancer express $\mathrm{MHC}$ I molecules, HSP70 and HSP90. DCs treated with these exosomes can promote $\mathrm{T}$ cell activation and produce cytotoxicity (148). DC-derived exosomes present antigens to DCs, and then these DCs can activate $\mathrm{T}$ cells. These results suggest that the exosome is a potential safe and feasible immunotherapy for advanced tumors (149). At present, the antitumor immunotherapy of exosomes derived from DCs is in phase II clinical trials of advanced malignant tumors.

Although DCs have antitumorigenic activity, their function may be inhibited in tumor immune microenvironment. The ovarian cancer microenvironment is rich in factors that inhibit monocyte differentiation into DCs. Ascites-derived exosomes from patients with ovarian cancer induce apoptosis in DCs by activation of the Fas/FasL pathway and mediating TRAIL apoptosis-inducing signal molecules in mature DC precursors. In one investigation, ovarian cancer-derived exosomes were cultured with dendritic precursor cells for $48 \mathrm{~h}$. Exosome co-cultured DCs had an apoptotic rate of $12.6 \%$ while the control group had an apoptotic rate of $8.6 \%$ (21). Overall, exosomes may induce apoptosis of DCs and stimulate precursors of mature DCs.

Mesenchymal stem cells. MSCs are an important member of the stem cell family, which play an important role in cancer progression. They are present, albeit in small numbers, in 


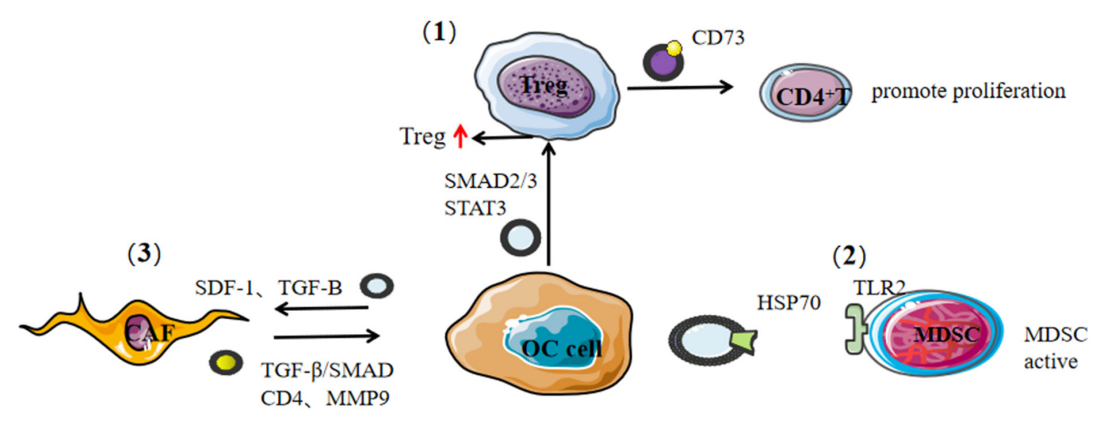

Figure 4. Exosomes mediate immune modulation. (1) Ovarian cancer cell-derived exosomes increase the amount of Treg cells and upregulate their immunosuppressive function. Treg-derived exosomes express CD73 to promote the proliferation of CD4 ${ }^{+} \mathrm{T}$ cell. (2) Ovarian cancer cell-derived exosomal HSP-70 binds with TLR2 to activate MDSCs and promote cancer progression. (3) Ovarian cancer cell-derived exosomes induce stem cells to differentiate into cancer-associated fibroblasts and upregulate tumorigenic factors (stromal cell-derived factor 1, TGF- $\beta$ ), and CAF-derived exosomes promote tumor cell proliferation. Treg, regulatory T cells; HSP, heat shock proteins; TLR2, toll-like receptor 2; MDSCs, myeloid-derived suppressor cells; CAF, cancer-associated fibroblasts; MMP, matrix metalloproteinase.

a variety of tissues (bone marrow, umbilical cord blood, umbilical cord, placenta and adipose) and are reported to have multidirectional differentiation and regeneration properties (150). In addition, MSCs also have the capability of immune modulation, which in a number of cases can cause immunosuppressive effects. De Miguel et al (151) demonstrated in vitro that MSCs can inhibit the proliferation of immune cells (lymphocytes, NK cells and DCs) and inhibit secretion of cytokines, thereby inhibiting the cytotoxic effect of $\mathrm{T}$ and NK cells via indoleamine 2,3-dioxygenase, while also activating and inducing the maturation of DCs. A co-culture of ovarian cancer cell lines (SKOV-3 and OVCAR-3) and MSCs demonstrates that adhesion, migration, invasion, proliferation and chemical resistance of ovarian cancer cells is enhanced, leading to accelerated tumorigenicity (152). In the tumor microenvironment, exosomes derived from MSCs also play an immunoregulatory role. Bone marrow MSC-derived exosomes have anti-inflammatory, anti-apoptotic, pro-angiogenic and immune-regulating effects (153). Bone marrow MSC-derived exosomes inhibit the proliferation of $\mathrm{T}$ and $\mathrm{B}$ cells and affect mRNA function; downregulating the expression of CXCL8 and marginal zone B and B1 cell-specific protein the level of IgM to affect the anti-tumorigenic function of B cells (154). MSC-derived exosomes upregulate MMP-2 and activate ecto-5'-nucleases, causing tumor cells to become more malignant and thus altering the tumor microenvironment, as well as enhancing tumor heterogeneity (155). In addition, cancer cell-derived exosomes affect the tumorigenicity of MSCs. In vitro analysis demonstrates that SKOV-3 and OVCAR-3 cell line-derived exosomes can enhance the migration capacity of MSCs (156). In the microenvironment of ovarian cancer, cancer stem cells are associated with creating drug resistance and making the tumor mass refractory to a specific drug $(147,157)$. Vera et al (158) have revealed that upon treatment with cisplatin, exosomes released by ovarian cancer that are rich in cancer stem cells can upregulate IL-6, IL-8 and VEGFA, increasing the migration capacity of cancer cells. In addition, factors secreted by MSCs can induce endothelial cell angiogenesis and accelerate the migration of low-invasive ovarian cancer cells. Exosomes have also been shown to enhance the oncogenicity of MSCs, leading to drug resistance and tumor progression (158). The expression of miR-146a in MSC-derived exosomes is upregulated, which targets laminin $\gamma-2$ to regulate the phosphoinositide 3-kinase (PI3K/Akt) signaling pathway. This subsequently inhibits the proliferation of ovarian cancer cells and induces chemotherapy resistance (159).

Previous studies have confirmed the antitumor effect of MSC-derived exosomes. Human adipose MSC-derived exosomes can induce apoptotic signals by upregulating pro-apoptotic signaling via BAX, CASP9, CASP3 and downregulating the anti-apoptotic protein BCL2 to inhibit A2780 and SKOV-3 cell proliferation, wound-repair and colony-forming ability (160). In mouse models of ovarian cancer, paclitaxel-loaded MSC-derived exosomes have strong antitumor effects, which suggests that they can be used as drug carriers to target ovarian cancer (161).

\section{Immunosuppressive effector cells}

The host immune system recognizes the tumor during progression, allowing immune cells to enter the tumor microenvironment under the action of chemokines. Subsequently, immune cells such as $\mathrm{CD} 4^{+} \mathrm{T}, \mathrm{CD} 8^{+} \mathrm{T}$, B lymphocytes, NK cells, macrophages and DCs are recruited to suppress the tumor in vivo. However, during the course of tumor development, immune monitoring through cancer immune editing is less selective for cancer cells that are less immunogenic, allowing them to escape the immune attack and thus achieve immune escape (Fig. 4). The clinical manifestations of tumor immune editing trigger the establishment of an immunosuppressive tumor microenvironment (112).

Tregs. Tregs negatively regulate the antitumor response in both a direct and indirect manner while also playing a key role in immune escape (162). The increase of Tregs in the tumor microenvironment of patients is related to poor prognosis and shortened overall survival (OS) time (55). Treg-derived exosomes can exert immunosuppressive effects by expressing CD73 and inhibiting the proliferation of $\mathrm{CD}^{+}{ }^{+} \mathrm{T}$ cells (107). Curiel et al (163) in 2004 analyzed 104 specimens of epithelial ovarian cancer and found that $\mathrm{CD} 4{ }^{+} \mathrm{CD} 25^{+} \mathrm{FOXP} 3^{+}$Tregs inhibited $\mathrm{T}$ cells in vivo and promoted tumor development. 
After tumor-derived exosomes activate Tregs, the expression levels of STAT3/SMAD2/3/IL-10/TGF-B increase and the expression of granzyme B, perforin and FasL are upregulated, thereby reducing the antitumor immune response. In addition, exosomes act on the SMAD2/3 and STAT3 signaling pathways to convert $\mathrm{CD} 4{ }^{+} \mathrm{CD} 25 \mathrm{~T}$ cells into $\mathrm{CD} 4{ }^{+} \mathrm{CD} 25^{+} \mathrm{FOXP} 3^{+}$ Tregs, which upregulates their immunosuppressive function and anti-apoptotic potential (164).

MDSCs. MDSC is an immunosuppressive cell of marrow-derived cells, which are induced to differentiate into DCs, macrophages and granulocytes. These MDSCs can depress the activity of T and NK cells, which can significantly suppress immune cell response (165). IL-6 is produced by autocrine activation in a Toll-like receptor 2 (TLR2)/myeloid differentiation primary response 88-dependent manner, triggering STAT3 activation and promoting the immunosuppressive function of MDSCs (166). A similar study found that HSP70 is highly expressed on the surface of ovarian cancer-derived exosomes, which fuses with and activates MDSCs by binding TLR2 to promote cancer progression $(166,167)$. Notably, the study found that the A8 peptide blocked this HSP70/TLR2 binding to weaken the ability of tumor-derived exosomes to activate MDSCs in a mouse model. Drugs, such as cisplatin and 5-fluorouracil, cause tumor cells to release more exosomes with HSP70 surface expression to activate MDSCs. When cisplatin or 5-fluorouracil is used in combination with A8 peptide, it can effectively antagonize the activation of MDSCs caused by cisplatin or 5-fluorouracil, which greatly enhances the antitumor effect of these drugs. Overall, this study has notable implications for novel ovarian cancer therapies (168).

CAFs. As an important element of the tumor microenvironment, CAFs secrete a variety of growth factors and pro-inflammatory cytokines (TGF- $\beta$, VEGF, IL- 6 and CXCL12) which promotes angiogenesis and recruits immunosuppressive cells into the tumor microenvironment to assist in immune evasion (169). Exosomes derived from epithelial ovarian cancerinduce adipose tissue-derived mesenchymal stem cells to differentiate into tumor-associated myofibroblasts and upregulate tumorigenic factors such as stromal cell-derived factor 1 and TGF- $\beta$ (170). TGF- $\beta$ receptor and SMAD signaling can regulate the expression of multifunctional proteoglycan VERISCAN protein, encoded by the $V C A N$ gene. Upregulating $V C A N$ activates the NF-kB signal pathway, which upregulates the expression of CD44, MMP-9 and hyaluronic acid-mediated motor receptors that collectively promote the migration and invasion of ovarian cancer cells (171). Further the CAF-derived exosomes can be internalized by SKOV-3 and CAOV-3 cell lines leading to a more aggressive tumorous phenotype, promoting the EMT of ovarian tumors. This evidence suggests that CAF-derived exosomes have the potential to provide a breakthrough in the treatment of ovarian cancer (172).

\section{Exosomal miRNAs, proteins and lipids in the tumor microenvironment}

Exosomes can carry a variety of biologically active molecules. miRNA is a type of non-coding RNA molecule (range, 9-25 nucleotides in length) encoded by an endogenous gene, that specifically binds to the 3'-untranslated region of target mRNA to effectively repress gene expression after it has been transcribed $(173,174)$. Cancer-associated adipocytes and CAFs transfer miR-21 to cancer cells via exosomes, thereby inhibiting ovarian cancer cell apoptosis (175). Releasing exosomal miRNA into the tumor microenvironment is a mechanism for reprogrammed gene expression at the epigenetic level. Ovarian cancer cells excrete unnecessary genetic material by releasing exosomes to maintain their aggressiveness and tumor immunogenicity (176-178). As a tumor-inhibiting factor, miR-6126 inhibits tumor progression by decreasing integrin $\beta 1 \mathrm{mRNA}$ level to promote metastatic behavior (177). miR-940 can inhibit ovarian cancer cell proliferation, colony formation, invasion and migration, and is highly expressed in exosomes derived from SKOV3-IP1, HeyA8 and HeyA8-MDR cell lines. Ovarian cancer cells enhance the tumorigenicity of cells through miRNA excretion mechanisms (178). A recent study provided supporting evidence that exosomes derived from epithelial ovarian cancer cells carry miR-141-3p, which activates the JAK/STAT3 and NF-kB signaling pathways in endothelial cells. This increases the level of VEGFR-2 in endothelial cells and enhances migration and angiogenesis (179). Exosomal miR-99a-5p derived from epithelial ovarian cancer cells affects human peritoneal mesothelial cells (HPMCs) by upregulating fibronectin and vitronectin to promote ovarian cancer progression (180). miRNAs carried by exosomes play a pro-tumorigenic role in the immune microenvironment of ovarian cancer (Table I).

In different ovarian cancer cell lines, the miRNA profile of exosomes varies. The miR-200 family inhibits EMT, which is only detected in the exosomes of poorly-invasive cell line OVCAR-3 (181). In a study of 109 patients with ovarian cancer and eight with ovarian cystadenoma, exosomal miRNA analysis revealed that miR-200b and miR-320 have a positive correlation with cellular proliferation and apoptosis. Additionally, the levels of exosomal miR-200b is related to cancer antigen 125 (CA125) and the OS rate of patients. Exosomal miR-200b has the potential to become a new prognostic indicator. The expression of miR-23a and miR-92a in ovarian cystadenoma-derived exosomes is lower compared with that of ovarian cancer-derived exosomes and exosomes derived from healthy individuals (182). Therefore, exosomal miRNAs can be used as biomarkers of ovarian cancer. In 2018 Kobayashi et al (183) found that miR-1290 is a potential biomarker for high-grade serous ovarian cancer and can be used to distinguish patients with other histologically malignant tumor types. This means that studying miRNAs carried by exosomes can provide new directions for the early diagnosis of ovarian cancer and in the search for novel and improved tumor markers for targeted therapy.

Proteomic analysis of ovarian cancer-derived exosomes revealed that these exosomes are rich in proteins related to antigen processing, and that they can effectively initiate antitumor immune responses (20). Exosomes from different types of malignant tumors show varying protein and lipid mass spectra. By comparing the proteome and lipid profiles of exosomes derived from SKOV-3 cell line and ovarian surface epithelial cells, it becomes clear that collagen $\alpha-2(\mathrm{~V})$ (also known as COL5A2) and lipoprotein lipase are highly expressed in SKOV-3 derived exosomes (184). Plus, CD44 
Table I. Role of exosomal miRNAs in the tumor microenvironment.

\begin{tabular}{|c|c|c|c|c|c|}
\hline Exosomal miRs & Source & Mechanism & Function & Recipient cells & (Refs.) \\
\hline $\operatorname{miR}-6126$ & Ovarian cancer & Release tumor suppressor & $\begin{array}{l}\text { Promote invasion and } \\
\text { migration }\end{array}$ & Ovarian cancer cell & $(177)$ \\
\hline miR-141-3p & Ovarian cancer & $\begin{array}{l}\text { Upregulate JAK/STAT3 and } \\
\text { NF-кb, VEGFR-2 }\end{array}$ & $\begin{array}{l}\text { Promote endothelial } \\
\text { cell angiogenesis }\end{array}$ & Endothelial cell & $(179)$ \\
\hline $\operatorname{miR}-99 a-5 p$ & Ovarian cancer & $\begin{array}{l}\text { Affect HPMCs via } \\
\text { fibronectin and } \\
\text { vitronectin upregulation }\end{array}$ & Promote invasion & $\begin{array}{l}\text { Human peritoneal } \\
\text { mesothelial cell }\end{array}$ & $(180)$ \\
\hline $\operatorname{miR}-200 b$ & $\begin{array}{l}\text { Ovarian } \\
\text { cancer plasma }\end{array}$ & $\begin{array}{l}\text { NA (Not discussed } \\
\text { in original research) }\end{array}$ & $\begin{array}{l}\text { Proliferation } \\
\text { and apoptosis }\end{array}$ & $\begin{array}{l}\text { OVCAR3 and } \\
\text { SKOV3 cell }\end{array}$ & $(182)$ \\
\hline $\operatorname{miR}-1290$ & Ovarian cancer & $\begin{array}{l}\text { NA (Not discussed in } \\
\text { original research) }\end{array}$ & Biomarker & & $(183)$ \\
\hline $\operatorname{miR}-222-3 p$ & $\begin{array}{l}\text { Ovarian } \\
\text { cancer }\end{array}$ & $\begin{array}{l}\text { Induce M2 } \\
\text { phenotype via SOCS3/STAT3 }\end{array}$ & $\begin{array}{l}\text { Induce TAM } \\
\text { and tumor progression }\end{array}$ & Macrophage & $(94)$ \\
\hline $\operatorname{miR}-1246$ & $\begin{array}{l}\text { Ovarian } \\
\text { cancer }\end{array}$ & $\begin{array}{l}\text { Cav1/p-GP/M2 } \\
\text { macrophage axis }\end{array}$ & Resistant to paclitaxel & Macrophage & $(194)$ \\
\hline $\operatorname{miR}-940$ & $\begin{array}{l}\text { Ovarian } \\
\text { cancer }\end{array}$ & $\begin{array}{l}\text { Induce macrophage } \mathrm{M} 2 \\
\text { polarization }\end{array}$ & $\begin{array}{l}\text { Promote proliferation and } \\
\text { metastasis }\end{array}$ & Macrophage & $(92)$ \\
\hline $\begin{array}{l}\operatorname{miR}-21-3 p \\
-125 b-5 p \text { and } \\
-181 d-5 p\end{array}$ & Ovarian cancer & $\begin{array}{l}\text { Induce macrophage } \mathrm{M} 2 \\
\text { polarization }\end{array}$ & $\begin{array}{l}\text { Promote proliferation and } \\
\text { metastasis }\end{array}$ & Macrophage & $(76)$ \\
\hline $\operatorname{miR}-223$ & Macrophage & PTEN-PI3K/AKT pathway & Promote drug resistance & Ovarian cancer cell & $(193)$ \\
\hline miR-7 & Macrophage & Inhibit EGFR/AKT/ ERK1/2 & Inhibit metastasis & Ovarian cancer cell & $(96)$ \\
\hline $\operatorname{miR}-221-3 p$ & $\begin{array}{l}\text { M2 } \\
\text { Macrophage }\end{array}$ & Inhibit CDKN1B & Promote proliferation & Ovarian cancer cell & (93) \\
\hline $\operatorname{miR}-21$ & CAF and CAA & $\begin{array}{l}\text { NA (Not discussed } \\
\text { in original research) }\end{array}$ & Inhibit apoptosis & Ovarian cancer cell & $(175)$ \\
\hline miR-98-5p & CAF & $\begin{array}{l}\text { Downregulate } \\
\text { CDKN1A }\end{array}$ & Resistant to cisplatin & Ovarian cancer cell & $(195)$ \\
\hline miR-146a & MSC & $\begin{array}{l}\text { LAMC2-P13K/Akt } \\
\text { signaling pathway. }\end{array}$ & $\begin{array}{l}\text { Inhibit proliferation and } \\
\text { chemotherapy resistance }\end{array}$ & Ovarian cancer cell & $(159)$ \\
\hline
\end{tabular}

AKT, protein kinase B; Cav1/p-gp, caveolin-1/ multidrug resistance protein 1; CDKN, cyclin-dependent kinase inhibitor; EGFR, epidermal growth factor receptor; ERK, extracellular signal-regulated kinases; HPMC, human peritoneal mesothelial cell; JAK/STAT, the Janus kinase/signal transducer and activator of transcription; LAMC2, laminin $\gamma 2$; PI3K, Phosphatidylinositol 3-kinase; PTEN, gene of phosphate and tension homology deleted on chromosome ten; SOCS/ STAT, suppressors of cytokine signaling/signal transducer and activator of transcription; VEGFR, vascular endothelial growth factor receptor.

is commonly found in the ovarian cancer-derived exosomes that become internalized by HPMCs. Increased expression of CD44 in HPMCs induces HPMCs to secrete MMP9 and allows HPMCs to clear the mesothelial barrier thus promoting cancer cell invasion and peritoneal metastasis (185). The ovarian cancer-derived exosomes promote tumor progression, and the proteins they carry have a role in malignancy of the tumor. These proteins include membrane proteins such as programmed cell death 6-interacting protein, tumor susceptibility gene 101, tetraspanins, HSPs and a variety of enzymes such as phosphate isomerase, peroxidase, aldehyde reductase and fatty acid synthase (186). Ovarian cancer cell-derived exosomes that overexpress LIN28 (an RNA-binding protein that promotes pluripotency) can enhance cell invasion and migration (187). HSP27 can also enhance the invasiveness and drug resistance of ovarian cancer and is a potential biological marker of ovarian cancer. Stope et al (188) demonstrated that exosomes can carry HSP27 secreted by OVCAR-3 and SKOV-3 cell lines to the tumor microenvironment, thereby promoting tumor progression.

\section{Significance of exosomes in ovarian cancer immunotherapy}

Cancer immunotherapy is a relatively new treatment option. By understanding the exosome profile and signal transduction mechanism, it can be better applied to cancer treatment. The advantages of exosomes are summarized as follows: i) Tumor-derived exosomes have the heterogeneity profile of tumor cells, ii) exosomes derived from homologous or 
allogeneic cells can reduce unnecessary immune responses, iii) exosomes have good stability, iv) the bio-distribution of exosomes can be adjusted by modifying the surface of exosomes to target a specific tumor location, v) exosomes have a long half-life and can improve the efficacy of drugs loaded into them as cargo and vi) exosomes have multiple types of internalization methods and can avoid the degradation of lysosomes, so as to efficiently transport drugs to the recipient cells.

At present, numerous achievements have been made in applying exosomes to cancer treatment. Small interfering RNAs and miRNAs carried by exosomes target and inhibit tumor cell proliferation and drug resistance (175). The reorganization of the exosomal membrane can improve the efficiency of drug loading and the sustained release of drugs (189). Exosomes can overcome the weak immunogenicity of tumor antigens that are likely to be used in a cancer vaccine (190). DC-derived exosomes can stimulate $\mathrm{T}$ cells by transporting MHC molecular complexes to the surface and facilitating $\mathrm{T}$ cells binding to tumor cells. At present, the antitumor immunotherapy of DC-derived exosomes has undergone II clinical trials in advanced non-smooth cell lung carcinoma, showing the feasibility and safety of antitumor exosome immunotherapy. It also has a new importance in ovarian cancer therapy (131). Exosomes derived from NK cells have a natural killing effect on melanomas, which is a potential cancer immunotherapy strategy (117) and exosomes have potential for ovarian cancer treatment.

In addition, exosomes can be used as carriers of antitumor drugs. In mouse models, a combination of mesenchymal stem cell-derived exosomes and paclitaxel increases the antitumor effect of paclitaxel (191). Previous studies have clarified the mechanism of miRNA generated resistance when carried by exosomes in ovarian cancer (192-194). Exosomes released by macrophages carry miR-223, which downregulates the PTEN-PI3K/AKT signaling pathway that can make ovarian cancer drug resistant (193). In addition, Kanlikilicer et al (194) demonstrated that miR-1246 expressed by ovarian cancer-derived exosomes can make ovarian cancer resistant to paclitaxel via the $\mathrm{Cav1/multidrug}$ resistance protein 1 (p-gp)/M2 phenotype macrophage axis, miR-1246 targets the Cavl gene and acts though platelet-derived growth factor receptor target recipient cells, induces polarization of M2 macrophages. Exosomes derived from CAFs carry miR-98-5p to promote the resistance of cisplatin in ovarian cancer (195). Using specific exosome inhibitors can effectively prevent this mechanism of drug resistance. Ovarian cancer-derived exosomes are enriched with DNA methyltransferase 1 that makes cancer cells resistant to cisplatin, but the exosomal inhibitor gw4869 can reverse this resistance and restore their drug sensitivity (196). This information will provide new avenues of exploration for targeted therapies against ovarian cancer. Cancer-derived exosomes can carry CRISPR/Cas9 to other ovarian cancer cells, inhibit PARP-1 expression, cause ovarian cancer cell apoptosis and enhance the sensitivity to cisplatin (197). Until now, there have been no reports on the application of exosomes to ovarian cancer immunotherapy, but it is an area should continue to be explored in the future.

\section{Conclusions}

As outlined in this article, the role of exosomes in the immune microenvironment of ovarian cancer can be described as a double-edged sword. Exosomes derived from immune cells can target tumor cells to exert antitumor immune effects. NK cell-derived exosomes mediate NK cell cytotoxicity through their surface receptors NKG2D and DNAX accessory molecule-1 (115,116); NK cell-derived exosomes can carry killer protein (CD56), FasL, perforin, granulysin, granzymes A and B to the tumor microenvironment of distant tumors (114). DC-derived exosomes can activate T cells to exert antitumor effects (145). Exosomes can also mediate cellular communication between immune cells. Mast cell-derived exosomes can promote the maturation of DCs (144). T cell-derived exosomes can regulate miRNA and TCR-rich vesicles to regulate gene expression and extracellular signal transduction of DCs (125). Treg-derived exosomes can inhibit $\mathrm{CD}^{+}{ }^{+} \mathrm{T}$ cell proliferation by expressing CD73 (140).

However, tumor cell-derived exosomes exert immunosuppression and immune escape through a variety of pathways in the tumor microenvironment. Exosomes derived from epithelial ovarian cancer can induce macrophages to differentiate into TAMs, downregulate the killing effect of NK cells on tumors, induce $\mathrm{T}$ cell apoptosis through Fas/FasL interactions and induce DC apoptosis. Ovarian cancer-derived exosomes also upregulate the functions of Tregs and MDSCs, induce the differentiation of CAFs and induce the tumorigenic activity of mesenchymal stem cells; forming a microenvironment that is beneficial to tumor proliferation, invasion, metastasis and tumor progression.

A study has shown that the tumor microenvironment contains functionally heterogeneous B lymphocytes and regulates tumor immunity by producing immunoglobulins and presenting costimulatory molecules (198). However, in ovarian cancer, research on the interaction between exosomes and B lymphocytes is rare, and is thus an area that requires further exploration. The regulation of the immune system by exosomes highlights the great potential of exosomes in cancer immunotherapy. The release of exosomes in patients with ovarian cancer is 3-4 times higher compared with in individuals without ovarian cancer. If the production of tumor-derived exosomes can be reduced, this could theoretically weaken the impact on immune suppression and thus would make immune escape more difficult. At present, preventing the excessive production of cancer cell-derived exosome has shown significant antitumor and anti-metastatic effects in breast cancer (199). If this technology can be applied to ovarian cancer, it will become a new strategy for ovarian cancer treatment.

Chemoresistance is common during the treatment of ovarian cancer and is usually associated with poor prognosis. Current biological techniques can effectively load chemotherapeutic drugs into exosomes through co-culture, electroporation or ultrasound (200). Studies have verified that exosomes loaded with paclitaxel and cisplatin can induce apoptosis of ovarian cancer cells $(175,192,194)$. If the exosomes loaded with paclitaxel and cisplatin can be used in clinical treatment, it will be a novel strategy for the treatment of drug-resistant ovarian cancer. Of course, this requires a large number of clinical trials for the verification of the treatment efficacy, and would require the joint efforts of various research centers and hospitals. At present, Clinicaltrials. gov (https://clinicaltrials.gov/) has reported 198 studies on 
exosomes, including three studies on exosomes as biomarkers of ovarian cancer, and one study on polycystic ovary syndrome and exosomes. There are no clinical trials using exosomes in the treatment of ovarian cancer, to the best of our knowledge. Before clinical trials, large-scale separation and purification of exosomes is still a huge challenge. Fortunately, research on the production of exosome mimics has made preliminary progress. Pisano et al (201) used monocytes as raw materials to produce exosome mimics through filters of different porosity and size exclusion chromatography columns. The development of immune-derived exosome mimics is expected to solve the problems of yield and reproducibility, which greatly improves the feasibility of applying exosomes to clinical trials (201).

The RNA, protein and lipid profiles of exosomes derived from different ovarian tumors are different, and the circular RNAs carried by ovarian tumor cell-derived exosomes are also different from healthy volunteers (134). In addition, serum exosomal piwi-interacting RNAs are considered to be a promising biomarker for patients with gastric cancer (202). Researchers have found that the detection level of CA125 in exosomes is higher compared with that in serum, which significantly improves the sensitivity of ovarian cancer diagnosis (203). This suggests that exosomes have the potential to become biomarkers for clinical analysis of ovarian cancer. With the development of biochips, microfluidic Raman biochips have been successfully used to monitor exosomes in prostate clinical serum samples (204). These devices can be similarly applied for ovarian cancer investigations based on exosomes.

\section{Acknowledgements}

Not applicable.

\section{Funding}

This study was supported by The National Natural Science Foundation of China (grant no. 81472761) and The Natural Science Foundation of Tianjin City (grant no. 14JCYBJC25300).

\section{Authors' contributions}

GYL designed the review. XL drafted the manuscript and prepared the figures. YL, TYZ, SSZ, JZZ, JW, and YS helped to modify the manuscript. All authors read and approved the final manuscript.

\section{Availability of data and materials}

Not applicable.

\section{Ethics approval and consent to participate}

Not applicable.

\section{Patient consent for publication}

Not applicable.

\section{Competing interests}

The authors declare that they have no competing interests.

\section{References}

1. Siegel RL, Miller KD and Jemal A: Cancer statistics, 2019. CA Cancer J Clin 69: 7-34, 2019.

2. Drakes ML and Stiff PJ: Regulation of ovarian cancer prognosis by immune cells in the tumor microenvironment. Cancers (Basel) 10: 302, 2018.

3. Gajewski TF, Schreiber H and Fu YX: Innate and adaptive immune cells in the tumor microenvironment. Nat Immunol 14: 1014-1022, 2013

4. Albini A, Bruno A, Noonan DM and Mortara L: Contribution to tumor angiogenesis from innate immune cells within the tumor microenvironment: Implications for immunotherapy. Front Immunol 9: 527, 2018.

5. Cassim S and Pouyssegur J: Tumor microenvironment: A metabolic player that shapes the immune response. Int J Mol Sci 21: 157, 2019.

6. Andre F, Schartz NE, Movassagh M, Flament C, Pautier P, Morice P, Pomel C, Lhomme C, Escudier B, Le Chevalier T, et al: Malignant effusions and immunogenic tumour-derived exosomes. Lancet 360: 295-305, 2002.

7. Giordano C, La Camera G, Gelsomino L, Barone I, Bonofiglio D, Ando $S$ and Catalano S: The biology of exosomes in breast cancer progression: Dissemination, immune evasion and metastatic colonization. Cancers (Basel) 12: 2179, 2020.

8. Kulkarni B, Kirave P, Gondaliya P, Jash K, Jain A, Tekade RK and Kalia K: Exosomal miRNA in chemoresistance, immune evasion, metastasis and progression of cancer. Drug Discov Today 24: 2058-2067, 2019.

9. Lundholm M, Schroder M, Nagaeva O, Baranov V, Widmark A, Mincheva-Nilsson L and Wikström P: Prostate tumor-derived exosomes down-regulate NKG2D expression on natural killer cells and CD8+ T cells: Mechanism of immune evasion. PLoS One 9: e108925, 2014.

10. Cheng L, Wu S, Zhang K, Qing Y and Xu T: A comprehensive overview of exosomes in ovarian cancer: Emerging biomarkers and therapeutic strategies. J Ovarian Res 10: 73, 2017.

11. Beach A, Zhang HG, Ratajczak MZ and Kakar SS: Exosomes: An overview of biogenesis, composition and role in ovarian cancer. J Ovarian Res 7: 14, 2014.

12. Doyle LM and Wang MZ: Overview of extracellular vesicles, their origin, composition, purpose, and methods for exosome isolation and analysis. Cells 8: 727, 2019.

13. Sharma A and Johnson A: Exosome DNA: Critical regulator of tumor immunity and a diagnostic biomarker. J Cell Physiol 235: 1921-1932, 2020.

14. Iliev D, Strandskog G, Nepal A, Aspar A, Olsen R, Jørgensen J, Wolfson D, Ahluwalia BS, Handzhiyski J and Mironova R: Stimulation of exosome release by extracellular DNA is conserved across multiple cell types. FEBS J 285: 3114-3133, 2018.

15. Tang YT, Huang YY, Zheng L, Qin SH, Xu XP, An TX, Xu Y, Wu YS, Hu XM, Ping BH and Wang Q: Comparison of isolation methods of exosomes and exosomal RNA from cell culture medium and serum. Int J Mol Med 40: 834-844, 2017.

16. Shyu KG, Wang BW, Pan CM, Fang WJ and Lin CM: Hyperbaric oxygen boosts long noncoding RNA MALAT1 exosome secretion to suppress microRNA-92a expression in therapeutic angiogenesis. Int J Cardiol 274: 271-278, 2019.

17. Hannafon BN, Trigoso YD, Calloway CL, Zhao YD, Lum DH, Welm AL, Zhao ZJ, Blick KE, Dooley WC and Ding WQ: Plasma exosome microRNAs are indicative of breast cancer. Breast Cancer Res 18: 90, 2016.

18. Kobayashi M, Sawada K, Miyamoto M, Shimizu A, Yamamoto M, Kinose Y, Nakamura K, Kawano M, Kodama M, Hashimoto K and Kimura T: Exploring the potential of engineered exosomes as delivery systems for tumor-suppressor microRNA replacement therapy in ovarian cancer. Biochem Biophys Res Commun 527: 153-161, 2020.

19. Mittal S, Gupta P, Chaluvally-Raghavan P and Pradeep S: Emerging role of extracellular vesicles in immune regulation and cancer progression. Cancers (Basel) 12: 3563, 2020. 
20. Liang B, Peng P, Chen S, Li L, Zhang M, Cao D, Yang J, Li H, Gui T, Li X and Shen K: Characterization and proteomic analysis of ovarian cancer-derived exosomes. J Proteomics 80: 171-182, 2013.

21. Peng P, Yan Y and Keng S: Exosomes in the ascites of ovarian cancer patients: Origin and effects on anti-tumor immunity. Oncol Rep 25: 749-762, 2011

22. Luo Z, Wang Q, Lau WB, Lau B, Xu L, Zhao L, Yang H, Feng M, Xuan Y, Yang Y, et al: Tumor microenvironment: The culprit for ovarian cancer metastasis? Cancer Lett 377: 174-182, 2016.

23. Da Silva AC, Jammal MP, Crispim PCA, Murta EFC and Nomelini RS: The role of stroma in ovarian cancer. Immunol Invest 49: 406-424, 2020.

24. Josephs SF, Ichim TE, Prince SM, Kesari S, Marincola FM, Escobedo AR and Jafri A: Unleashing endogenous TNF-alpha as a cancer immunotherapeutic. J Transl Med 16: 242, 2018.

25. Wen Z, Liu H, Li M, Li B, Gao W, Shao Q, Fan B, Zhao F Wang Q, Xie Q, et al: Increased metabolites of 5-lipoxygenase from hypoxic ovarian cancer cells promote tumor-associated macrophage infiltration. Oncogene 34: 1241-1252, 2015.

26. Browning L, Patel MR, Horvath EB, Tawara K and Jorcyk CL: IL-6 and ovarian cancer: Inflammatory cytokines in promotion of metastasis. Cancer Manag Res 10: 6685-6693, 2018.

27. Sanmarco LM, Ponce NE, Visconti LM, Eberhardt N, Theumer MG, Minguez AR and Aoki MP: IL-6 promotes M2 macrophage polarization by modulating purinergic signaling and regulates the lethal release of nitric oxide during Trypanosoma cruzi infection. Biochim Biophys Acta Mol Basis Dis 1863 857-869, 2017

28. Yin Z, Ma T, Lin Y, Lu X, Zhang C, Chen S and Jian Z: IL-6/STAT3 pathway intermediates M1/M2 macrophage polarization during the development of hepatocellular carcinoma. J Cell Biochem 119: 9419-9432, 2018.

29. Fu XL, Duan W, Su CY, Mao FY, Lv YP, Teng YS, Yu PW, Zhuang Y and Zhao YL: Interleukin 6 induces M2 macrophage differentiation by STAT3 activation that correlates with gastric cancer progression. Cancer Immunol Immunother 66: 1597-1608, 2017.

30. Jiang B, Zhu SJ, Xiao SS and Xue M: miR-217 Inhibits M2-like macrophage polarization by suppressing secretion of interleukin-6 in ovarian cancer. Inflammation 42: 1517-1529, 2019.

31. McLean K, Tan L, Bolland DE, Coffman LG, Peterson LF, Talpaz M, Neamati N and Buckanovich RJ: Leukemia inhibitory factor functions in parallel with interleukin- 6 to promote ovarian cancer growth. Oncogene 38: 1576-1584, 2019.

32. Wang Y, Zong X, Mitra S, Mitra AK, Matei D and Nephew KP. IL-6 mediates platinum-induced enrichment of ovarian cancer stem cells. JCI Insight 3: e122360, 2018.

33. Bretz NP, Ridinger J, Rupp AK, Rimbach K, Keller S, Rupp C, Marmé F, Umansky L, Umansky V, Eigenbrod T, et al: Body fluid exosomes promote secretion of inflammatory cytokines in monocytic cells via Toll-like receptor signaling. J Biol Chem 288: 36691-3702, 2013.

34. De Marco M, Falco A, Festa M, Raffone A, Sandullo L, Rosati A, Reppucci F, Cammarota AL, Esposito F, Matassa DS, et al: Different mechanisms underlie IL-6 release in chemosensitive and chemoresistant ovarian carcinoma cells. Am J Cancer Res 10: 2596-2602, 2020

35. Kumari N, Dwarakanath BS, Das A and Bhatt AN: Role of interleukin-6 in cancer progression and therapeutic resistance. Tumour Biol 37: 11553-11572, 2016.

36. Wang Y, Niu XL, Qu Y, Wu J, Zhu YQ, Sun WJ and Li LZ: Autocrine production of interleukin- 6 confers cisplatin and paclitaxel resistance in ovarian cancer cells. Cancer Lett 295 $110-123,2010$

37. Kampan NC, Madondo MT, Reynolds J, Hallo J, McNally OM, Jobling TW, Stephens AN, Quinn MA and Plebanski M: Pre-operative sera interleukin-6 in the diagnosis of high-grade serous ovarian cancer. Sci Rep 10: 2213, 2020.

38. Isobe A, Sawada K, Kinose Y, Ohyagi-Hara C, Nakatsuka E, Makino H, Ogura T, Mizuno T, Suzuki N, Morii E, et al: Interleukin 6 receptor is an independent prognostic factor and a potential therapeutic target of ovarian cancer. PLoS One 10 : e0118080, 2015

39. Yuan X, Zhang J, Li D, Mao Y, Mo F, Du W and Ma X: Prognostic significance of tumor-associated macrophages in ovarian cancer: A meta-analysis. Gynecol Oncol 147: 181-187, 2017.

40. Maccio A, Gramignano G, Cherchi MC, Tanca L, Melis L and Madeddu C: Role of M1-polarized tumor-associated macrophages in the prognosis of advanced ovarian cancer patients. Sci Rep 10: 6096, 2020
41. Carroll MJ, Kapur A, Felder M, Patankar MS and Kreeger PK: M2 macrophages induce ovarian cancer cell proliferation via a heparin binding epidermal growth factor/matrix metalloproteinase 9 intercellular feedback loop. Oncotarget 7: 86608-86620, 2016.

42. Zhou ZN, Sharma VP, Beaty BT, Roh-Johnson M, Peterson EA, Van Rooijen N, Kenny PA, Wiley HS, Condeelis JS and Segall JE: Autocrine HBEGF expression promotes breast cancer intravasation, metastasis and macrophage-independent invasion in vivo. Oncogene 33: 3784-3793, 2014

43. Haque S and Morris JC: Transforming growth factor- $\beta$ : A therapeutic target for cancer. Hum Vaccin Immunother 13: 1741-1750, 2017.

44. Steitz AM, Steffes A, Finkernagel F, Unger A, Sommerfeld L, Jansen JM, Wagner U, Graumann J, Müller R and Reinartz S: Tumor-associated macrophages promote ovarian cancer cell migration by secreting transforming growth factor beta induced (TGFBI) and tenascin C. Cell Death Dis 11: 249, 2020.

45. Dasari S, Fang Y and Mitra AK: Cancer associated fibroblasts: Naughty neighbors that drive ovarian cancer progression. Cancers (Basel) 10: 406, 2018.

46. Gao Q, Yang Z, Xu S, Li X, Yang X, Jin P, Liu Y, Zhou X, Zhang T, Gong $\mathrm{C}$, et al: Heterotypic CAF-tumor spheroids promote early peritoneal metastatis of ovarian cancer. J Exp Med 216: 688-703, 2019.

47. Zhuang J, Lu Q, Shen B, Huang X, Shen L, Zheng X, Huang R, Yan J and Guo H: TGF $\beta 1$ secreted by cancer-associated fibroblasts induces epithelial-mesenchymal transition of bladder cancer cells through lncRNA-ZEB2NAT. Sci Rep 5: 11924, 2015.

48. Kan T, Wang W, Ip PP, Zhou S, Wong AS, Wang X and Yang M: Single-cell EMT-related transcriptional analysis revealed intra-cluster heterogeneity of tumor cell clusters in epithelial ovarian cancer ascites. Oncogene 39: 4227-4240, 2020.

49. Han Q, Huang B, Huang Z, Cai J, Gong L, Zhang Y, Jiang J, Dong W and Wang Z: Tumor cell-fibroblast heterotypic aggregates in malignant ascites of patients with ovarian cancer. Int J Mol Med 44: 2245-2255, 2019.

50. Liu CL, Pan HW, Torng PL, Fan MH and Mao TL: SRPX and HMCN1 regulate cancer-associated fibroblasts to promote the invasiveness of ovarian carcinoma. Oncol Rep 42: 2706-2715, 2019.

51. De Cicco P, Ercolano G and Ianaro A: The new era of cancer immunotherapy: Targeting myeloid-derived suppressor cells to overcome immune evasion. Front Immunol 11: 1680, 2020.

52. Sasidharan Nair V and Elkord E: Immune checkpoint inhibitors in cancer therapy: A focus on T-regulatory cells. Immunol Cell Biol 96: 21-33, 2018.

53. Li X, Wang J, Wu W, Gao H, Liu N, Zhan G, Li L, Han L and Guo X: Myeloid-derived suppressor cells promote epithelial ovarian cancer cell stemness by inducing the CSF2/p-STAT3 signalling pathway. FEBS J 287: 5218-5235, 2020.

54. Horikawa N, Abiko K, Matsumura N, Hamanishi J, Baba T, Yamaguchi K, Yoshioka Y, Koshiyama M and Konishi I: Expression of vascular endothelial growth factor in ovarian cancer inhibits tumor immunity through the accumulation of myeloid-derived suppressor cells. Clin Cancer Res 23: 587-599, 2017.

55. Dutsch-Wicherek MM, Szubert S, Dziobek K, Wisniewski M, Lukaszewska E, Wicherek L, Jozwicki W, Rokita W and Koper K: Analysis of the treg cell population in the peripheral blood of ovarian cancer patients in relation to the long-term outcomes. Ginekol Pol 90: 179-184, 2019.

56. Batlle E and Massague J: Transforming growth Factor-beta signaling in immunity and cancer. Immunity 50: 924-940, 2019.

57. Zhou J, Jiang W, Huang W, Ye M and Zhu X: Prognostic values of transforming growth Factor-Beta subtypes in ovarian cancer. Biomed Res Int 2020: 2170606, 2020.

58. Wen H, Qian M, He J, Li M, Yu Q and Leng Z: Inhibiting of self-renewal, migration and invasion of ovarian cancer stem cells by blocking TGF-beta pathway. PLoS One 15: e0230230, 2020.

59. Bai Y, Li LD, Li J, Chen RF, Yu HL, Sun HF, Wang JY and Lu X. A FXYD5/TGF $\beta / S M A D$ positive feedback loop drives epithelial-to-mesenchymal transition and promotes tumor growth and metastasis in ovarian cancer. Int J Oncol 56: 301-314, 2020.

60. Fukui S, Nagasaka K, Miyagawa Y, Kikuchi-Koike R, Kawata Y, Kanda R, Ichinose T, Sugihara T, Hiraike H, Wada-Hiraike O, et al: The proteasome deubiquitinase inhibitor bAP15 downregulates TGF- $\beta /$ Smad signaling and induces apoptosis via UCHL5 inhibition in ovarian cancer. Oncotarget 10: 5932-5948, 2019 
61. Kulbe H, Chakravarty P, Leinster DA, Charles KA, Kwong J, Thompson RG, Coward JI, Schioppa T, Robinson SC, Gallagher WM, et al: A dynamic inflammatory cytokine network in the human ovarian cancer microenvironment. Cancer Res 72: 66-75, 2012.

62. Carbotti G, Petretto A, Naschberger E, Sturzl M, Martini S, Mingari MC, Filaci G, Ferrini S and Fabbi M. Cytokine-Induced Guanylate Binding Protein 1 (GBP1) release from human ovarian cancer cells. Cancers (Basel) 12: 488, 2020.

63. Zhao H, Yang L, Baddour J, Achreja A, Bernard V, Moss T, Marini JC, Tudawe T, Seviour EG, San Lucas FA, et al: Tumor microenvironment derived exosomes pleiotropically modulate cancer cell metabolism. Elife 5: e10250, 2016.

64. Whiteside TL: The effect of tumor-derived exosomes on immune regulation and cancer immunotherapy. Future Oncol 13: 2583-2592, 2017

65. Gong M, Yu B, Wang J, Wang Y, Liu M, Paul C, Millard RW, Xiao DS, Ashraf $\mathrm{M}$ and $\mathrm{Xu} \mathrm{M}$ : Mesenchymal stem cells release exosomes that transfer miRNAs to endothelial cells and promote angiogenesis. Oncotarget 8: 45200-45212, 2017.

66. Wu Q, Zhou L, Lv D, Zhu X and Tang H: Exosome-mediated communication in the tumor microenvironment contributes to hepatocellular carcinoma development and progression. J Hematol Oncol 12: 53, 2019.

67. Dorayappan KDP, Wanner R, Wallbillich JJ, Saini U,Zingarelli R, Suarez AA, Cohn DE and Selvendiran K: Hypoxia-induced exosomes contribute to a more aggressive and chemoresistant ovarian cancer phenotype: A novel mechanism linking STAT3/Rab proteins. Oncogene 37: 3806-3821, 2018

68. Matias Ostrowski NBC, Sophie Krumeich, Isabelle Fanget, Graça Raposo, Ariel Savina, et al: Rab27a and Rab27b control different steps of the exosome secretion pathway. Nat Cell Biol 12: 19-30, 2010.

69. Qiu JJ, Lin XJ, Tang XY, Zheng TT, Lin YY and Hua KQ Exosomal metastasis associated lung adenocarcinoma Transcript 1 promotes angiogenesis and predicts poor prognosis in epithelial ovarian cancer. Int J Biol Sci 14: 1960-1973, 2018.

70. Tang MKS, Yue PYK, Ip PP, Huang RL, Lai HC, Cheung ANY, Tse KY, Ngan HYS and Wong AST: Soluble E-cadherin promotes tumor angiogenesis and localizes to exosome surface. Nat Commun 9: 2270, 2018.

71. Runz S, Keller S, Rupp C, Stoeck A, Issa Y, Koensgen D, Mustea A, Sehouli J, Kristiansen G and Altevogt P: Malignant ascites-derived exosomes of ovarian carcinoma patients contain CD24 and EpCAM. Gynecol Oncol 107: 563-571, 2007.

72. Lei X, Lei Y, Li JK, Du WX, Li RG, Yang J, Li J, Li F and Tan HB: Immune cells within the tumor microenvironment: Biological functions and roles in cancer immunotherapy. Cancer Lett 470: 126-133, 2020.

73. Xu SJ, Hu HT, Li HL and Chang S: The role of miRNAs in immune cell development, immune cell activation, and tumor immunity: With a focus on macrophages and natural killer cells. Cells 8: 1140, 2019.

74. Rhee I: Diverse macrophages polarization in tumor microenvironment. Arch Pharm Res 39: 1588-1596, 2016.

75. Tashiro-Yamaji J, Kubota T and Yoshida R: Macrophage MHC receptor 2: A novel receptor on allograft $(\mathrm{H}-2 \mathrm{D}(\mathrm{d}) \mathrm{K}(\mathrm{d}))$-induced macrophage $(\mathrm{H}-2 \mathrm{D}(\mathrm{b}) \mathrm{K}(\mathrm{b}))$ recognizing an MHC class I molecule, $\mathrm{H}-2 \mathrm{~K}(\mathrm{~d})$, in mice. Gene 384: 1-8, 2006.

76. Chen X, Zhou J, Li X, Wang X, Lin Y and Wang X: Exosomes derived from hypoxic epithelial ovarian cancer cells deliver microRNAs to macrophages and elicit a tumor-promoted phenotype. Cancer Lett 435: 80-91, 2018.

77. Ruffell B, Affara NI and Coussens LM: Differential macrophage programming in the tumor microenvironment. Trends Immunol 33: 119-126, 2012.

78. Shapouri-Moghaddam A, Mohammadian S, Vazini H, Taghadosi M, Esmaeili SA, Mardani F, Seifi B, Mohammadi A, Afshari JT and Sahebkar A: Macrophage plasticity, polarization, and function in health and disease. J Cell Physiol 233: 6425-6440, 2018.

79. Funes SC, Rios M,Escobar-Vera J and Kalergis AM. Implications of macrophage polarization in autoimmunity. Immunology 154 186-195, 2018.

80. Madeddu C, Gramignano G, Kotsonis P, Coghe F, Atzeni V, Scartozzi M and Macciò A: Microenvironmental M1 tumor-associated macrophage polarization influences cancer-related anemia in advanced ovarian cancer: Key role of interleukin-6. Haematologica 103: e388-e391, 2018.
81. Reinartz S, Schumann T, Finkernagel F, Wortmann A, Jansen JM, Meissner W, Krause M, Schwörer AM, Wagner U, Müller-Brüsselbach S and Müller R: Mixed-polarization phenotype of ascites-associated macrophages in human ovarian carcinoma: Correlation of CD163 expression, cytokine levels and early relapse. Int J Cancer 134: 32-42, 2014.

82. Nowak M and Klink M: The role of tumor-associated macrophages in the progression and chemoresistance of ovarian cancer. Cells 9: 1299, 2020.

83. Zhu Q, Wu X, Wu Y and Wang X: Interaction between Treg cells and tumor-associated macrophages in the tumor microenvironment of epithelial ovarian cancer. Oncol Rep 36: 3472-3478, 2016.

84. Zhou J, Li X, Wu X, Zhang T, Zhu Q, Wang X, Wang H, Wang K, Lin $\mathrm{Y}$ and Wang X: Exosomes released from tumor-associated macrophages transfer miRNAs that induce a Treg/Th17 cell imbalance in epithelial ovarian cancer. Cancer Immunol Res 6: 1578-1592, 2018.

85. Huang YJ, Huang TH, Yadav VK, Sumitra MR, Tzeng DT, Wei PL, Shih JW and Wu AT: Preclinical investigation of ovatodiolide as a potential inhibitor of colon cancer stem cells via downregulating sphere-derived exosomal beta-catenin/STAT3/miR-1246 cargoes. Am J Cancer Res 10: 2337-2354, 2020.

86. Xiao L, He Y, Peng F, Yang J and Yuan C: Endometrial cancer cells promote M2-like macrophage polarization by delivering exosomal miRNA-21 under hypoxia condition. J Immunol Res 2020: 9731049, 2020.

87. Wang X, Luo G, Zhang K, Cao J, Huang C, Jiang T, Liu B, Su L and Qiu Z: Hypoxic tumor-derived exosomal miR-301a Mediates M2 macrophage polarization via PTEN/PI3K gamma to promote pancreatic cancer metastasis. Cancer Res 78: 4586-4598, 2018.

88. Bardi GT, Smith MA and Hood JL: Melanoma exosomes promote mixed M1 and M2 macrophage polarization. Cytokine 105: 63-72, 2018

89. Li X, Lei Y, Wu M and Li N: Regulation of macrophage activation and polarization by HCC-derived exosomal lncRNA TUC339. Int J Mol Sci 19: 2958, 2018.

90. Piao YJ, Kim HS, Hwang EH, Woo J, Zhang M and Moon WK: Breast cancer cell-derived exosomes and macrophage polarization are associated with lymph node metastasis. Oncotarget 9: 7398-7410, 2018.

91. Pritchard A, Tousif S, Wang Y, Hough K, Khan S, Strenkowski J, Chacko BK, Darley-Usmar VM and Deshane JS: Lung tumor cell-derived exosomes promote M2 macrophage polarization. Cells 9: 1303, 2020.

92. Chen X, Ying X, Wang X, Wu X, Zhu Q and Wang X: Exosomes derived from hypoxic epithelial ovarian cancer deliver microRNA-940 to induce macrophage M2 polarization. Oncol Rep 38: 522-528, 2017.

93. Li X and Tang M: Exosomes released from M2 macrophages transfer miR-221-3p contributed to EOC progression through targeting CDKN1B. Cancer Med 9: 5976-5988, 2020.

94. Ying X, Wu Q, Wu X, Zhu Q, Wang X, Jiang L, Chen X and Wang $X$ : Epithelial ovarian cancer-secreted exosomal miR-222-3p induces polarization of tumor-associated macrophages. Oncotarget 7: 43076-43087, 2016.

95. Wu Q, Wu X, Ying X, Zhu Q, Wang X, Jiang L, Chen X, Wu Y and Wang X: Suppression of endothelial cell migration by tumor associated macrophage-derived exosomes is reversed by epithelial ovarian cancer exosomal lncRNA. Cancer Cell Int 17: 62, 2017.

96. Hu Y, Li D, Wu A, Qiu X, Di W, Huang L and Qiu L: TWEAK-stimulated macrophages inhibit metastasis of epithelial ovarian cancer via exosomal shuttling of microRNA. Cancer Lett 393: 60-67, 2017

97. Baj-Krzyworzeka M, Szatanek R, Weglarczyk K, Baran J and Zembala M: Tumour-derived microvesicles modulate biological activity of human monocytes. Immunol Lett 113: 76-82, 2007.

98. Baj-Krzyworzeka M, Baran J, Weglarczyk K, Szatanek R, Szaflarska A, Siedlar M and Zembala M: Tumour-derived microvesicles (TMV) mimic the effect of tumour cells on monocyte subpopulations. Anticancer Res 30: 3515-3520, 2010.

99. Baj-Krzyworzeka M, Mytar B, Szatanek R, Surmiak M, Weglarczyk K, Baran J and Siedlar M: Colorectal cancer-derived microvesicles modulate differentiation of human monocytes to macrophages. J Transl Med 14: 36, 2016.

100. Moradi-Chaleshtori M, Bandehpour M, Soudi S Mohammadi-Yeganeh S and Hashemi SM: In vitro and in vivo evaluation of anti-tumoral effect of M1 phenotype induction in macrophages by miR-130 and miR-33 containing exosomes. Cancer Immunol Immunother 2020 (Epub ahead of print). 
101. Yue S, Ye X, Zhou T, Gan D, Qian H, Fang W, Yao M, Zhang D, Shi $\mathrm{H}$ and Chen T: PGRN ${ }^{-1}$ TAMs-derived exosomes inhibit breast cancer cell invasion and migration and its mechanism exploration. Life Sci 264: 118687, 2020.

102. Han JJ, Yu M, Houston N, Steinberg SM and Kohn EC: Progranulin is a potential prognostic biomarker in advanced epithelial ovarian cancers. Gynecol Oncol 120: 5-10, 2011.

103. Carlson AM, Maurer MJ, Goergen KM, Kalli KR, Erskine CL, Behrens MD, Knutson KL and Block MS: Utility of progranulin and serum leukocyte protease inhibitor as diagnostic and prognostic biomarkers in ovarian cancer. Cancer Epidemiol Biomarkers Prev 22: 1730-1735, 2013.

104. Dong T, Yang D, Li R, Zhang L, Zhao H, Shen Y, Zhang X, Kong $\mathrm{B}$ and Wang L: PGRN promotes migration and invasion of epithelial ovarian cancer cells through an epithelial mesenchymal transition program and the activation of cancer associated fibroblasts. Exp Mol Pathol 100: 17-25, 2016.

105. Dou R, Hong Z, Tan X, Hu F, Ding Y, Wang W, Liang Z, Zhong R, Wu X and Weng X: Fas/FasL interaction mediates imbalanced cytokine/cytotoxicity responses of iNKT cells against Jurkat cells. Mol Immunol 99: 145-153, 2018.

106. Wallin RP, Screpanti V, Michaelsson J, Grandien A and Ljunggren HG: Regulation of perforin-independent NK cell-mediated cytotoxicity. Eur J Immunol 33: 2727-2735, 2003.

107. Tanaka H, Kai S, Yamaguchi M, Misawa M, Fujimori Y, Yamamoto $\mathrm{M}$ and Hara H: Analysis of natural killer (NK) cell activity and adhesion molecules on NK cells from umbilical cord blood. Eur J Haematol 71: 29-38, 2003

108. Konjevic GM, Vuletic AM, Mirjacic Martinovic KM,Larsen AK and Jurisic VB: The role of cytokines in the regulation of NK cells in the tumor environment. Cytokine 117: 30-40, 2019.

109. Pahl JHW, Cerwenka A and Ni J: Memory-Like NK Cells Remembering a previous activation by cytokines and NK cell receptors. Front Immunol 9: 2796, 2018.

110. Gianchecchi E, Delfino DV and Fierabracci A: NK cells in autoimmune diseases: Linking innate and adaptive immune responses. Autoimmun Rev 17: 142-154, 2018.

111. Zitti B and Bryceson YT: Natural killer cells in inflammation and autoimmunity. Cytokine Growth Factor Rev 42: 37-46, 2018

112. Rodriguez GM, Galpin KJC, McCloskey CW and Vanderhyden BC: The tumor microenvironment of epithelial ovarian cancer and its influence on response to immunotherapy. Cancers (Basel) 10: 242, 2018

113. Zhu L, Kalimuthu S, Oh JM, Gangadaran P, Baek SH, Jeong SY, Lee SW, Lee J and Ahn BC: Enhancement of antitumor potency of extracellular vesicles derived from natural killer cells by IL-15 priming. Biomaterials 190-191: 38-50, 2019.

114. Jong AY, Wu CH, Li J, Sun J, Fabbri M, Wayne AS and Seeger RC: Large-scale isolation and cytotoxicity of extracellular vesicles derived from activated human natural killer cells. J Extracell Vesicles 6: 1294368, 2017.

115. Lugini L, Cecchetti S, Huber V, Luciani F, Macchia G, Spadaro F, Paris L, Abalsamo L, Colone M, Molinari A, et al: Immune surveillance properties of human NK cell-derived exosomes. J Immunol 189: 2833-2842, 2012

116. Di Pace A, Tumino N, Besi F, Alicata C, Conti LA, Munari E, Maggi E, Vacca P and Moretta L: Characterization of human NK cell-derived exosomes: Role of DNAM1 receptor in exosome-mediated cytotoxicity against tumor. Cancers (Basel) 12: 661, 2020.

117. Zhu L, Kalimuthu S, Gangadaran P, Oh JM, Lee HW, Baek SH, Jeong SY, Lee SW, Lee J and Ahn BC: Exosomes derived from natural killer cells exert therapeutic effect in melanoma. Theranostics 7: 2732-2745, 2017.

118. Neviani P, Wise PM, Murtadha M, Liu CW, Wu CH, Jong AY, Seeger RC and Fabbri M: Natural killer-derived exosomal miR-186 inhibits neuroblastoma growth and immune escape mechanisms. Cancer Res 79: 1151-1164, 2019.

119. Terrén I, Orrantia A, Vitallé J, Zenarruzabeitia O and Borrego F: NK cell metabolism and tumor microenvironment. Front Immunol 10: 2278, 2019

120. Labani-Motlagh A, Israelsson P, Ottander U, Lundin E, Nagaev I, Nagaeva $O$, Dehlin E, Baranov V and Mincheva-Nilsson L: Differential expression of ligands for NKG2D and DNAM-1 receptors by epithelial ovarian cancer-derived exosomes and its influence on NK cell cytotoxicity. Tumour Biol 37: 5455-5466, 2016.

121. Ishii S and Koziel MJ: Immune responses during acute and chronic infection with hepatitis $\mathrm{C}$ virus. Clin Immunol 128: 133-147, 2008.
122. Kaech SM and Cui W: Transcriptional control of effector and memory CD8+ T cell differentiation. Nat Rev Immunol 12: 749-761, 2012.

123. Thommen DS and Schumacher TN: T cell dysfunction in cancer. Cancer Cell 33: 547-562, 2018

124. Hiltbrunner S, Larssen P, Eldh M, Martinez-Bravo MJ, Wagner AK, Karlsson MC and Gabrielsson S: Exosomal cancer immunotherapy is independent of MHC molecules on exosomes. Oncotarget 7: 38707-38717, 2016.

125. Torralba D, Baixauli F, Villarroya-Beltri C,Fernández-Delgado I, Latorre-Pellicer A, Acín-Pérez R, Martín-Cófreces NB, Jaso-Tamame ÁL, Iborra S, Jorge I, et al: Priming of dendritic cells by DNA-containing extracellular vesicles from activated $\mathrm{T}$ cells through antigen-driven contacts. Nat Commun 9: 2658, 2018.

126. Raposo G, Nijman HW, Stoorvogel W, Liejendekker R, Harding CV, Melief CJ and Geuze HJ: B lymphocytes secrete antigen-presenting vesicles. J Exp Med 183: 1161-1172, 1996.

127. Yang J, Bi L, He X, Wang Z, Qian Y, Xiao L and Shi B: Follicular helper $T$ cell derived exosomes promote $B$ cell proliferation and differentiation in antibody-mediated rejection after renal transplantation. Biomed Res Int 2019: 6387924, 2019

128. Fernandez-Messina L, Rodriguez-Galan A, de Yebenes VG, Gutierrez-Vazquez C, Tenreiro S, Seabra MC, Ramiro AR and Sánchez-Madrid F: Transfer of extracellular vesicle-microRNA controls germinal center reaction and antibody production. EMBO Rep 21: e48925, 2020.

129. Li Y, Yang Y, Xiong A, Wu X, Xie J, Han S and Zhao S: Comparative gene expression analysis of lymphocytes treated with exosomes derived from ovarian cancer and ovarian cysts. Front Immunol 8: 607, 2017.

130. Xu HY, Li N, Yao N, Xu XF, Wang HX, Liu XY and Zhang Y: CD8+ T cells stimulated by exosomes derived from RenCa cells mediate specific immune responses through the FasL/Fas signaling pathway and, combined with GM-CSF and IL-12, enhance the anti-renal cortical adenocarcinoma effect. Oncol Rep 42: 866-879, 2019.

131. Taylor DD, Gercel-Taylor C, Lyons KS, Stanson J and Whiteside TL: T-Cell apoptosis and suppression of T-Cell Receptor/CD3-zeta by Fas Ligand-Containing membrane vesicles shed from ovarian tumors. Clin Cancer Res 9: 5113-5119, 2003.

132. Abusamra AJ, Zhong Z, Zheng X, Li M, Ichim TE, Chin JL and Min WP: Tumor exosomes expressing Fas ligand mediate CD8+ T-cell apoptosis. Blood Cells Mol Dis 35: 169-173, 2005.

133. Filipazzi P, Burdek M, Villa A, Rivoltini L and Huber V: Recent advances on the role of tumor exosomes in immunosuppression and disease progression. Semin Cancer Biol 22: 342-349, 2012.

134. Wang X, Yao Y and Jin M: Circ-0001068 is a novel biomarker for ovarian cancer and inducer of PD1 expression in T cells. Aging (Albany NY) 12: 19095-19106, 2020.

135. Asare-Werehene M, Communal L, Carmona E, Han Y, Song YS, Burger D, Mes-Masson AM and Tsang BK: Plasma gelsolin inhibits $\mathrm{CD} 8^{+} \mathrm{T}$-cell function and regulates glutathione production to confer chemoresistance in ovarian cancer. Cancer Res 80: 3959-3971, 2020

136. Taylor DD and Gercel-Taylor C: Tumour-derived exosomes and their role in cancer-associated T-cell signalling defects. $\mathrm{Br}$ J Cancer 92: 305-311, 2005.

137. Shenoy GN, Loyall J, Berenson CS, Kelleher RJ Jr, Iyer V, Balu-Iyer SV, Odunsi K and Bankert RB: Sialic Acid-Dependent inhibition of T Cells by Exosomal Ganglioside GD3 in ovarian tumor microenvironments. J Immunol 201: 3750-3758, 2018.

138. Webb TJ, Li X, Giuntoli RL II, Lopez PH, Heuser C, Schnaar RL, Tsuji M, Kurts C, Oelke M and Schneck JP: Molecular identification of GD3 as a suppressor of the innate immune response in ovarian cancer. Cancer Res 72: 3744-3752, 2012.

139. Shenoy GN, Loyall J, Maguire O, Iyer V, Kelleher RJ Jr, Minderman H, Wallace PK, Odunsi K, Balu-Iyer SV and Bankert RB: Exosomes Associated with human ovarian tumors harbor a reversible checkpoint of T-cell Responses. Cancer Immunol Res 6: 236-247, 2018.

140. Clayton A, Al-Taei S, Webber J, Mason MD and Tabi Z: Cancer exosomes express CD39 and CD73, which suppress T cells through adenosine production. J Immunol 187: 676-683, 2011.

141. Kelleher RJ Jr, Balu-Iyer S, Loyall J, Sacca AJ, Shenoy GN, Peng P, Iyer V, Fathallah AM, Berenson CS, Wallace PK, et al: Extracellular vesicles present in human ovarian tumor microenvironments induce a Phosphatidylserine-Dependent arrest in the T-cell signaling cascade. Cancer Immunol Res 3: 1269-1278, 2015 . 
142. Li X and Wang X: The emerging roles and therapeutic potential of exosomes in epithelial ovarian cancer. Mol Cancer 16: 92, 2017.

143. Wang Y, Xiang Y, Xin VW, Wang XW, Peng XC, Liu XQ, Wang D, Li N, Cheng JT, Lyv YN, et al: Dendritic cell biology and its role in tumor immunotherapy. J Hematol Oncol 13: 107, 2020.

144. Skokos D, Botros HG, Demeure C, Morin J, Peronet R, Birkenmeier G, Boudaly S and Mécheri S: Mast cell-derived exosomes induce phenotypic and functional maturation of dendritic cells and elicit specific immune responses in vivo. J Immunol 170: 3037-3045, 2003

145. Robbins PD and Morelli AE: Regulation of immune responses by extracellular vesicles. Nat Rev Immunol 14: 195-208, 2014.

146. Lindenbergh MFS, Koerhuis DGJ, Borg EGF, van 't Veld EM, Driedonks TAP, Wubbolts R, Stoorvogel W and Boes M: Bystander T-Cells Support Clonal T-Cell activation by controlling the release of dendritic Cell-Derived Immune-Stimulatory extracellular vesicles. Front Immunol 10: 448, 2019.

147. Zheng L, Li Z, Ling W, Zhu D, Feng Z and Kong L: Exosomes derived from dendritic cells attenuate liver injury by modulating the balance of Treg and Th17 Cells after ischemia reperfusion. Cell Physiol Biochem 46: 740-756, 2018.

148. Li QL, Bu N, Yu YC, Hua W and Xin XY: Exvivo experiments of human ovarian cancer ascites-derived exosomes presented by dendritic cells derived from umbilical cord blood for immunotherapy treatment. Clin Med Oncol 2: 461-467, 2008

149. Pitt JM, André F, Amigorena S, Soria JC, Eggermont A, Kroemer G and Zitvogel L: Dendritic cell-derived exosomes for cancer therapy. J Clin Invest 126: 1224-1232, 2016.

150. Ridge SM, Sullivan FJ and Glynn SA: Mesenchymal stem cells: Key players in cancer progression. Mol Cancer 16: 31, 2017.

151. De Miguel MP, Fuentes-Julián S, Blázquez-Martínez A, Pascual CY, Aller MA, Arias J and Arnalich-Montiel F: Immunosuppressive properties of mesenchymal stem cells: Advances and applications. Curr Mol Med 12: 574-591, 2012.

152. Lis R, Touboul C, Raynaud CM, Malek JA, Suhre K, Mirshahi M and Rafii A: Mesenchymal cell interaction with ovarian cancer cells triggers pro-metastatic properties. PLoS One 7: e38340, 2012

153. Zhang B, Tian X, Hao J, Xu G and Zhang W: Mesenchymal Stem Cell-Derived extracellular vesicles in tissue regeneration. Cell Transplant 29: 963689720908500, 2020.

154. Khare D, Or R, Resnick I, Barkatz C, Almogi-Hazan O and Avni B: Mesenchymal stromal Cell-Derived exosomes affect mRNA expression and function of B-Lymphocytes. Front Immunol 9: 3053, 2018.

155. Yang Y, Bucan V, Baehre H, von der Ohe J, Otte A and Hass R: Acquisition of new tumor cell properties by MSC-derived exosomes. Int J Oncol 47: 244-252, 2015.

156. Sharma S, Alharbi M, Kobayashi M, Lai A, Guanzon D, Zuniga F, Ormazabal V, Palma C, Scholz-Romero K, Rice GE, et al: Proteomic analysis of exosomes reveals an association between cell invasiveness and exosomal bioactivity on endothelial and mesenchymal cell migration in vitro. Clin Sci (Lond) 132 2029-2044, 2018.

157. Dean M, Fojo T and Bates S: Tumour stem cells and drug resistance. Nat Rev Cancer 5: 275-284, 2005.

158. Vera N, Acuna-Gallardo S, Grunenwald F, Caceres-Verschae A, Realini O, Acuna R, Lladser A, Illanes SE and Varas-Godoy M: Small extracellular vesicles released from ovarian cancer spheroids in response to Cisplatin Promote the Pro-Tumorigenic activity of mesenchymal stem cells. Int J Mol Sci 20: 4972, 2019

159. Qiu L, Wang J, Chen M, Chen F and Tu W: Exosomal microRNA-146a derived from mesenchymal stem cells increases the sensitivity of ovarian cancer cells to docetaxel and taxane via a LAMC2-mediated PI3K/Akt axis. Int J Mol Med 46: 609-620, 2020

160. Reza AMMT, Choi YJ, Yasuda H and Kim JH: Human adipose mesenchymal stem cell-derived exosomal-miRNAs are critical factors for inducing anti-proliferation signalling to A2780 and SKOV-3 ovarian cancer cells. Sci Rep 6: 38498, 2016.

161. Melzer C, Rehn V, Yang Y, Bahre H, von der Ohe J and Hass R: Taxol-Loaded MSC-Derived exosomes provide a therapeutic vehicle to target metastatic breast cancer and other carcinoma cells. Cancers (Basel) 11: 798, 2019.

162. Tanaka A and Sakaguchi S: Regulatory T cells in cancer immunotherapy. Cell Res 27: 109-118, 2017.

163. Curiel TJ, Coukos G, Zou L, Alvarez X, Cheng P, Mottram P, Evdemon-Hogan M, Conejo-Garcia JR, Zhang L, Burow M, et al Specific recruitment of regulatory $T$ cells in ovarian carcinoma fosters immune privilege and predicts reduced survival. Nat Med 10: 942-949, 2004.
164. Szajnik M, Czystowska M, Szczepanski MJ, Mandapathil M and Whiteside TL: Tumor-derived microvesicles induce, expand and up-regulate biological activities of human regulatory T cells (Treg). PLoS One 5: e11469, 2010.

165. Gabrilovich DI: Myeloid-Derived suppressor cells. Cancer Immunol Res 5: 3-8, 2017.

166. Chalmin F, Ladoire S, Mignot G, Vincent J, Bruchard M, Remy-Martin JP, Boireau W, Rouleau A, Simon B, Lanneau D, et al: Membrane-associated Hsp72 from tumor-derived exosomes mediates STAT3-dependent immunosuppressive function of mouse and human myeloid-derived suppressor cells. J Clin Invest 120: 457-471, 2010.

167. Balaburski GM, Leu JI, Beeharry N, Hayik S, Andrake MD, Zhang G, Herlyn M, Villanueva J, Dunbrack RL Jr, Yen T, et al: A modified HSP70 inhibitor shows broad activity as an anticancer agent. Mol Cancer Res 11: 219-229, 2013

168. Gobbo J, Marcion G, Cordonnier M, Dias AMM, Pernet N, Hammann A, Richaud S, Mjahed H, Isambert N, Clausse V, et al: Restoring anticancer immune response by targeting Tumor-Derived exosomes with a HSP70 Peptide Aptamer. J Natl Cancer Inst 108, 2015 (Epub ahead of print).

169. Liu T, Han C, Wang S, Fang P, Ma Z, Xu L and Yin R: Cancer-associated fibroblasts: An emerging target of anti-cancer immunotherapy. J Hematol Oncol 12: 86, 2019.

170. Cho JA, Park H, Lim EH, Kim KH, Choi JS, Lee JH, Shin JW and Lee KW: Exosomes from ovarian cancer cells induce adipose tissue-derived mesenchymal stem cells to acquire the physical and functional characteristics of tumor-supporting myofibroblasts. Gynecol Oncol 123: 379-386, 2011.

171. Yeung TL, Leung CS, Wong KK, Samimi G, Thompson MS Liu J, Zaid TM, Ghosh S, Birrer MJ and Mok SC: TGF- $\beta$ modulates ovarian cancer invasion by upregulating CAF-derived versican in the tumor microenvironment. Cancer Res 73: 5016-5028, 2013.

172. Li W, Zhang X, Wang J, Li M, Cao C, Tan J, Ma D and Gao Q: TGF $\beta 1$ in fibroblasts-derived exosomes promotes epithelial-mesenchymal transition of ovarian cancer cells. Oncotarget 8: 96035-96047, 2017.

173. Lu TX and Rothenberg ME: MicroRNA. J Allergy Clin Immunol 141: 1202-1207, 2018.

174. Zhang J, Li S, Li L, Li M, Guo C, Yao J and Mi S: Exosome and exosomal microRNA: Trafficking, sorting, and function. Genomics Proteomics Bioinformatics 13: 17-24, 2015.

175. Au Yeung CL, Co NN, Tsuruga T, Yeung TL, Kwan SY, Leung CS, Li Y, Lu ES, Kwan K, Wong KK, et al: Exosomal transfer of stroma-derived miR21 confers paclitaxel resistance in ovarian cancer cells through targeting APAF1. Nat Commun 7: 11150, 2016.

176. Dickman CT, Lawson J, Jabalee J, MacLellan SA, LePard NE, Bennewith KL and Garnis C: Selective extracellular vesicle exclusion of miR-142-3p by oral cancer cells promotes both internal and extracellular malignant phenotypes. Oncotarget 8: 15252-15266, 2017.

177. Kanlikilicer P, Rashed MH, Bayraktar R, Mitra R, Ivan C, Aslan B,Zhang X, Filant J, Silva AM, Rodriguez-Aguayo C, et al: Ubiquitous release of exosomal tumor suppressor miR-6126 from ovarian cancer cells. Cancer Res 76: 7194-7207, 2016.

178. Rashed MH, Kanlikilicer P, Rodriguez-Aguayo C, Pichler M, Bayraktar R, Bayraktar E, Ivan C, Filant J, Silva A, Aslan B, et al: Exosomal miR-940 maintains SRC-mediated oncogenic activity in cancer cells: A possible role for exosomal disposal of tumor suppressor miRNAs. Oncotarget 8: 20145-20164, 2017

179. Masoumi-Dehghi S, Babashah S and Sadeghizadeh M: MicroRNA-141-3p-containing small extracellular vesicles derived from epithelial ovarian cancer cells promote endothelial cell angiogenesis through activating the JAK/STAT3 and NF- $\kappa$ B signaling pathways. J Cell Commun Signal 14: 233-244, 2020

180. Yoshimura A, Sawada K, Nakamura K, Kinose Y, Nakatsuka E, Kobayashi M, Miyamoto M, Ishida K, Matsumoto Y, Kodama M, et al: Exosomal miR-99a-5p is elevated in sera of ovarian cancer patients and promotes cancer cell invasion by increasing fibronectin and vitronectin expression in neighboring peritoneal mesothelial cells. BMC Cancer 18: 1065, 2018.

181. Kobayashi M, Salomon C, Tapia J, Illanes SE, Mitchell MD and Rice GE: Ovarian cancer cell invasiveness is associated with discordant exosomal sequestration of Let-7 miRNA and miR-200. J Transl Med 12: 4, 2014 
182.Pan C, Stevic I, Muller V, Ni Q, Oliveira-Ferrer L, Pantel K and Schwarzenbach H: Exosomal microRNAs as tumor markers in epithelial ovarian cancer. Mol Oncol 12: 1935-1948, 2018

183. Kobayashi M, Sawada K, Nakamura K, Yoshimura A, Miyamoto M, Shimizu A, Ishida K, Nakatsuka E, Kodama M, Hashimoto K, et al: Exosomal miR-1290 is a potential biomarker of high-grade serous ovarian carcinoma and can discriminate patients from those with malignancies of other histological types. J Ovarian Res 11: 81, 2018.

184. Cheng L, Zhang K, Qing Y, Li D, Cui M, Jin P and Xu T: Proteomic and lipidomic analysis of exosomes derived from ovarian cancer cells and ovarian surface epithelial cells. J Ovarian Res 13: 9, 2020.

185. Nakamura K, Sawada K, Kinose Y, Yoshimura A, Toda A, Nakatsuka E, Hashimoto K, Mabuchi S, Morishige KI, Kurachi $\mathrm{H}$, et al: Exosomes promote ovarian cancer cell invasion through transfer of CD44 to peritoneal mesothelial cells. Mol Cancer Res 15: 78-92, 2017.

186. Dorayappan KDP, Wallbillich JJ, Cohn DE and Selvendiran K: The biological significance and clinical applications of exosomes in ovarian cancer. Gynecol Oncol 142: 199-205, 2016.

187. Enriquez VA, Cleys ER, Da Silveira JC, Spillman MA Winger QA and Bouma GJ: High LIN28A expressing ovarian cancer cells secrete exosomes that induce invasion and migration in HEK293 cells. Biomed Res Int 2015: 701390, 2015.

188. Stope MB, Klinkmann G, Diesing K, Koensgen D, Burchardt M and Mustea A: Heat Shock Protein HSP27 secretion by ovarian cancer cells is linked to intracellular expression levels, occurs independently of the endoplasmic reticulum pathway and HSP27's phosphorylation status, and is mediated by exosome liberation. Dis Markers 2017: 1575374, 2017.

189. Nam GH, Choi Y, Kim GB, Kim S, Kim SA and Kim IS Emerging prospects of exosomes for cancer treatment: From conventional therapy to immunotherapy. Adv Mater 32: e2002440, 2020.

190. Koyama Y, Ito T, Hasegawa A, Eriguchi M, Inaba T, Ushigusa T and Sugiura K: Exosomes derived from tumor cells genetically modified to express Mycobacterium tuberculosis antigen: A novel vaccine for cancer therapy. Biotechnol Lett 38: 1857-1866, 2016.

191. Kalimuthu S, Gangadaran P, Rajendran RL, Zhu L, Oh JM, Lee HW, Gopal A, Baek SH, Jeong SY, Lee SW, et al: A new approach for loading anticancer drugs into mesenchymal stem Cell-Derived exosome mimetics for cancer therapy. Front Pharmacol 9: 1116, 2018

192. Feng Y, Hang W, Sang Z, Li S, Xu W, Miao Y, Xi X and Huang Q: Identification of exosomal and non-exosomal microRNAs associated with the drug resistance of ovarian cancer. Mol Med Rep 19: 3376-3392, 2019.
193. Zhu X, Shen H, Yin X, Yang M, Wei H, Chen Q, Feng F, Liu Y, Xu W and Li Y: Macrophages derived exosomes deliver miR-223 to epithelial ovarian cancer cells to elicit a chemoresistant phenotype. J Exp Clin Cancer Res 38: 81, 2019.

194. Kanlikilicer P, Bayraktar R, Denizli M, Rashed MH, Ivan C, Aslan B, Mitra R, Karagoz K, Bayraktar E, Zhang X, et al: Exosomal miRNA confers chemo resistance via targeting Cav1/p-gp/M2-type macrophage axis in ovarian cancer. EBioMedicine 38: 100-112, 2018

195. Guo H, Ha C, Dong H, Yang Z, Ma Y and Ding Y: Cancerassociated fibroblast-derived exosomal microRNA-98-5p promotes cisplatin resistance in ovarian cancer by targeting CDKN1A. Cancer Cell Int 19: 347, 2019.

196. Cao YL, Zhuang T, Xing BH, Li N and Li Q: Exosomal DNMT1 mediates cisplatin resistance in ovarian cancer. Cell Biochem Funct 35: 296-303, 2017

197. Kim SM, Yang Y, Oh SJ, Hong Y, Seo M and Jang M: Cancer-derived exosomes as a delivery platform of CRISPR/Cas9 confer cancer cell tropism-dependent targeting. J Control Release 266: 8-16, 2017.

198. Tsou P, Katayama H, Ostrin EJ and Hanash SM: The emerging role of B Cells in tumor immunity. Cancer Res 76: 5597-5601, 2016.

199. Im EJ, Lee CH, Moon PG, Rangaswamy GG, Lee B, Lee JM, Lee JC, Jee JG, Bae JS, Kwon TK, et al: Sulfisoxazole inhibits the secretion of small extracellular vesicles by targeting the endothelin receptor A. Nat Commun 10: 1387, 2019.

200. Walker S, Busatto S, Pham A, Tian M, Suh A, Carson K, Quintero A, Lafrence M, Malik H, Santana MX and Wolfram J: Extracellular vesicle-based drug delivery systems for cancer treatment. Theranostics 9: 8001-8017, 2019.

201. Pisano S, Pierini I, Gu J, Gazze A, Francis LW, Gonzalez D, Conlan RS and Corradetti B: Immune (Cell) Derived Exosome Mimetics (IDEM) as a treatment for ovarian cancer. Front Cell Dev Biol 8: 553576, 2020.

202. Ge L, Zhang N, Li D, Wu Y, Wang H and Wang J: Circulating exosomal small RNAs are promising non-invasive diagnostic biomarkers for gastric cancer. J Cell Mol Med 24: 14502-14513, 2020.

203. Chen Z, Liang Q, Zeng H, Zhao Q, Guo Z, Zhong R, Xie M, Cai X, $\mathrm{Su}$ J, He Z, et al: Exosomal CA125 as a promising biomarker for ovarian cancer diagnosis. J Cancer 11: 6445-6453, 2020.

204. Wang Y, Li Q, Shi H, Tang K, Qiao L, Yu G, Ding C and Yu S: Microfluidic Raman biochip detection of exosomes: A promising tool for prostate cancer diagnosis. Lab Chip 20: 4632-4637, 2020.

This work is licensed under a Creative Commons Attribution-NonCommercial-NoDerivatives 4.0 International (CC BY-NC-ND 4.0) License. 